\title{
Enquête sur la provenance et les pérégrinations de deux livres d'Heures enluminés du XVe siècle conservés aux Archives des jésuites au Canada*
}

\author{
JOHANNE BIRON
}

Société historique de Montréal

\begin{abstract}
Les Relations et le Journal des jésuites attestèrent la présence de livres d'Heures en Nouvelle-France au XVII siècle. À la même époque, les hospitalières de l'Hôtel-Dieu de Québec réclamaient des livres d'Heures auprès de leurs bienfaiteurs européens, perpétuant certaines pratiques de dévotion héritées du Moyen-Âge et de la Renaissance. Deux livres d'Heures du XV siècle sont conservés aux Archives des jésuites au Canada. Cette enquête vise à retracer les routes que purent emprunter les deux manuscrits avant d'entrer dans les Archives du Collège Sainte-Marie fondées en 1844 par le père Félix Martin. À la fin du XIXe et au début XXe siècle, les deux livres furent mis en valeur par le père Arthur Edward Jones, dans le cadre d'expositions consacrées aux manuscrits des premiers missionnaires jésuites en Amérique du Nord. Cette enquête vise aussi à prendre la mesure de l'intérêt que ces Heures suscitèrent chez les bibliophiles jésuites et laïcs.
\end{abstract}

The Jesuit Relations and the Journal des jésuites attest to the presence of Books of Hours in New France during the seventeenth century. At the same time, the Hospitallers of the Hôtel-Dieu in Quebec were demanding Books of Hours from their European benefactors, thus continuing certain devotional practices inherited from the Middle Ages and the Renaissance. Two Books of Hours from the fifteenth century are preserved at the Archive of the Jesuits in Canada. This inquiry is aimed at retracing the routes that the two manuscripts had taken before arriving at the Archive of the College Sainte-Marie, which was founded in 1844 by Father Felix Martin. At the end of the nineteenth and the beginning of the twentieth century, the two books were given pride of place by Father Arthur Edward Jones at the centre of expositions devoted to manuscripts of the first Jesuit missionaries in North America. This investigation is additionally aimed at assessing the interest taken in these Hours among Jesuit bibliophiles and the laity.

\footnotetext{
*Nous remercions madame Theresa Rowat de nous avoir aimablement accordé l'autorisation de reproduire dans cet article de précieux documents originaux qui sont conservés aux Archives des jésuites au Canada. La reproduction d'autres documents a par ailleurs été rendue possible grâce à la collaboration du projet Inventaire des imprimés anciens du Québec (IMAQ) et de Bibliothèque et Archives nationales du Québec (BAnQ). Enfin, la recherche et la rédaction de cet article ont été réalisées grâce à une subvention du CRSH (2014-2018) accordée au projet sur les livres d'Heures conservés au Québec, sous la direction de Brenda Dunn-Lardeau.
} 
Au père André Gendron, s.j.

«[...] je serais enchanté de savoir que je ne suis pas le seul qui essai[e] de d[é]mêler les faits embrouillés de nos anciennes missions » (Père Arthur Edward Jones, s.j., au père Camille de Rochemonteix, s.j.,

15 avril $\left.1890^{1}\right)$

$\mathrm{D}$ eux livres d'Heures enluminés qui furent la propriété des Archives du Collège Sainte-Marie sont conservés aujourd'hui aux Archives des jésuites au Canada, à Montréal, sous les cotes MS-009-in-8 (ou 0900-0011.2.1) et MS-1 In-12 (ou 0900-0010.2.1). Le premier livre, les Heures de Philippe de Montholon, est un manuscrit du $\mathrm{XV}^{\mathrm{e}}$ siècle dont deux des propriétaires connus sont Philippe de Montholon, lieutenant général au bailliage de Chalon-surSaône, et son gendre, Jean Fyot, seigneur d'Arbois et conseiller au Parlement de Bourgogne 2 . Le second livre est un manuscrit du $\mathrm{XV}^{\mathrm{e}}$ siècle (vers 1470) qui porte les marques de possession manuscrites « $\mathrm{PB}$ », « $\mathrm{P}$ Bouthillier » et "PBouthillier» (voir fig. 1) ${ }^{3}$. Au nombre des rares marques d'appartenance postérieures à la composition des manuscrits, seules les estampilles du Collège

1. Extrait de la copie d'une lettre dactylographiée du père Arthur Edward Jones, s.j., envoyée au père Camille de Rochemonteix, s.j., à Rouen, le 15 avril 1890 (Archives des jésuites au Canada (AJC)). Fonds Arthur Edward Jones, s.j., BO-0035-9, 4 et Fonds Édouard Désy, s.j., BO-0078-13, 85). Le père Arthur Edward Jones fut, de 1882 à 1918, l’archiviste des Archives du Collège Sainte-Marie, fondées à Montréal par le père Félix Martin en 1844. Le jésuite Camille de Rochemonteix est l'auteur de deux grands ouvrages parus en 1895-1896 et 1906 : Les jésuites et la Nouvelle-France au XVII' siècle, d’après beaucoup de documents inédits et Les jésuites et la Nouvelle-France au XVIII siècle, d’après des documents inédits.

2. Nous avons également relevé l'inscription «B_M_Cona[n]t 1776 » (ou « B_ M_Cona[r]t 1776 ») sur le feuillet collé au revers du plat supérieur.

3. Dans un rapport d’expertise quelle remit aux Archives de la Compagnie de Jésus au Canada français en juillet 2002, Susanne Marie Holm, responsable de latelier de restauration des œuvres sur papier du Centre de conservation du Québec (CCQ), datait « le plus petit livre des heures [...] de ca. 1470 et le plus grand, Livre des heures de Feste, [...] de 1522 »(Susanne Marie Holm, Rapport d'expertise, Dossier OP 200221 [Centre de conservation du Québec, 8 juillet 2002], 1). Par ailleurs, une description de ces deux manuscrits faite d’après les documents et transcriptions conservés aux Archives des jésuites au Canada a été proposée par Didier Méhu, «Les livres d'heures manuscrits conservés dans les collections publiques du Québec », ainsi que par Patrice Hamel et Guillaume Simard, « Les Heures de Philippe de Montholon, livre d'heures picard du XVe siècle (Montréal, Archives des jésuites au Canada, MS-009-in-8 ${ }^{\circ}$ ) ", Memini : travaux et documents (Les livres d'heures manuscrits conservés dans les collections publiques du Québec), dir. Didier Méhu 17 (2013), http://memini.revues.org/455. Pour plus de précisions sur les deux 
Sainte-Marie et de ses Archives ${ }^{4}$, qui se trouvent dans l'un des deux livres, témoignent explicitement du lien qui les unit aux jésuites du Canada français 5 . Les feuillets reliés des deux manuscrits ne révèlent donc aucun itinéraire de transmission précis, qui permettrait de savoir à quel moment et dans quelles circonstances ces livres sont entrés dans les collections montréalaises. Pourtant, nous savons qu'ils figuraient, dès la fin du XIX ${ }^{e}$ siècle, parmi les plus précieuses pièces manuscrites que les jésuites du Canada consentaient à prêter dans le cadre d'expositions qui mettaient en valeur leurs premières missions en Amérique du Nord.

C'est, par le fait même, dans les écrits missionnaires de la NouvelleFrance, plus précisément dans les Relations et le Journal des jésuites, que nous devrons chercher les premières allusions à des livres d'Heures ou de dévotion, voire à des livres-reliques, qui ont pu prendre une valeur singulière aux yeux des pères de la Compagnie de Jésus. D’ailleurs, dans les longues listes de « choses necessaires pour le soulagement des pauvres malades de l'Hospital de Kebec ${ }^{6}$ qui étaient ajoutées aux Relations et publiées à leur suite, la Mère Supérieure des religieuses hospitalières prenait généralement soin de demander des

enlumineurs des Heures de Philippe de Montholon, de même que sur des liens établis avec des manuscrits semblables, voir l'introduction de Brenda Dunn-Lardeau.

4. Le Fonds général portait autrefois le nom de " Archives du Collège Ste-Marie » (ACSM). À partir de 1967, les Archives du Collège Sainte-Marie ne formèrent plus qu'une partie de l'ensemble des fonds réunis sous le nom de "Archives de la Compagnie de Jésus au Canada français » (ASJCF par la suite). Les ASJCF furent transportées à la résidence Notre-Dame-de-Montserrat, à Saint-Jérôme, en 1968. Dans la première décennie du XXI ${ }^{e}$ siècle, les administrations jésuites du pays décidèrent de fusionner les centres d'archives du Canada français et du Canada anglais. Le nouveau centre des Archives des jésuites au Canada (AJC) fut inauguré à Montréal en 2009. Consulter, au sujet de cette histoire, les remarques du père Joseph Cossette (AJC. Archives, Collège Sainte-Marie, Q-0001, CACSM 1, 3040-9, fol. $2 \mathrm{r}^{\circ}$ ) ainsi que le site des Archives des jésuites au Canada (http://archivesjesuites.ca/fr/). Voir aussi : AJC. Fonds Arthur Melançon, s.j., BO-0080-4, 5f.

5. Les Heures de Philippe de Montholon (MS-009-in- $8^{\circ}$ ) portent les ex-libris estampillés : " Collège SteMarie. 1160 rue Bleury. Montréal » et « Coll. Stæ. Mariæ. Montis-Regii Archivum ». Aucun ex-libris du Collège Sainte-Marie n’a été relevé dans le manuscrit MS-1 In- $12^{\circ}$.

6. Reuben Gold Thwaites, éd., The Jesuit Relations and Allied Documents : Travels and Explorations of the Jesuit Missionaries in New France, 1610-1791, 73 vols. (Cleveland : The Burrows Brothers Company, 1899), vol. 50 : doc. CXVIII, 160. Toutes les références aux Relations des jésuites éditées par Reuben Gold Thwaites sont tirées de cette édition. 
livrets de dévotion, des « Heures de la Vierge $»^{7}$ ou des « Petites Heures pour prier Dieu $»^{8}$, perpétuant ainsi certaines pratiques de dévotion conservatrices héritées du Moyen Âge et de la Renaissance, avec lesquelles l'Europe catholique post-tridentine semblait pourtant toujours familière, puisqu'il s'imprimait encore beaucoup d'Heures au XVII' siècle?.

Les décennies qui suivirent le retour et le rétablissement des jésuites au Canada, en 1842, au terme d'une absence de quarante-deux ans, furent marquées par la recherche soutenue de manuscrits originaux qui avaient été dispersés « aux quatre vents $~^{10}$ à la mort, en 1800 , du dernier jésuite du Régime français, le père Jean-Joseph Casot. Dès son arrivée dans le Bas-Canada en 1842, le père Félix Martin entreprit de rassembler ces documents épars ${ }^{11}$. En 1844, il visita les archives des hospitalières de l'Hôtel-Dieu de Québec, en compagnie de son ami et mécène, le collectionneur Jacques Viger, et y découvrit le dépôt des manuscrits des anciens jésuites de la Nouvelle-France que le père Casot avait laissé entre les mains des religieuses ${ }^{12}$. Ces dernières rendirent aux jésuites une partie des archives de leur ancien collège de Québec, lors de la création à Montréal, par le père Martin, des Archives du Collège Sainte-Marie, où devaient être déposés les manuscrits et la correspondance inédite de la Compagnie de Jésus ${ }^{13}$.

Comme nous le verrons, les deux livres d'Heures du $\mathrm{XV}^{\mathrm{e}}$ siècle, qui furent classés parmi les plus précieux trésors du Collège Sainte-Marie au XIX ${ }^{\mathrm{e}}$ siècle,

7. Thwaites, The Jesuit Relations, vol. 49 : doc. CXVII, 210.

8. Thwaites, The Jesuit Relations, vol. 50 : doc. CXVIII, 162.

9. Albert Labarre, "Heures (Livres d'Heures) ", Dictionnaire de spiritualité ascétique et mystique : doctrine et histoire (Paris : Beauchesne, 1969), VII/1, col. 423.

10. Copie d'une lettre dactylographiée du père Arthur Edward Jones, s.j., envoyée au père Camille de Rochemonteix, s.j., à Rouen, le 15 avril 1890 (AJC. Fonds Arthur Edward Jones, s.j., BO-0035-9, 4). Voir plus haut n. 1.

11. Voir Georges-Émile Giguère, "Martin, Félix », Dictionnaire biographique du Canada (Université Laval / University of Toronto, 2003-), vol. XI, consulté le 21 avril 2015, http://www.biographi.ca/fr/bio/ martin_felix_11F. html.

12. Voir Paul Desjardins, s.j., "Nos archives », Lettres du Bas-Canada XXII (mars-décembre 1968) : 32-33. Voir aussi, au sujet de cet article, les remarques du père Joseph Cossette (AJC. Fonds Archives, Collège Sainte-Marie, 3040).

13. "Bibliographie générale (Archives de la Compagnie de Jésus, Province du Canada français) ", Dictionnaire biographique du Canada, vol. IV, consulté le 22 avril 2015, http://www.biographi.ca/fr/ biblio/4. 
occupèrent une place de choix dans les catalogues d'expositions organisées en 1892, 1894, 1897, 1899 et 1904, à côté des manuscrits des missionnaires de la Nouvelle-France. À défaut, à ce point-ci de nos recherches, de pouvoir dire avec exactitude entre quelles mains ces manuscrits enluminés passèrent au fil des siècles, nous tenterons de saisir au mieux la valeur historique et symbolique dont ils se chargèrent en Amérique. La résurgence, à la fin du XIX ${ }^{e}$ siècle, jusque dans les années 1960, d'un intérêt marqué pour ces deux livres d'Heures du XV siècle, en particulier chez les jésuites du Canada, mérite d'être appréhendée comme un phénomène durable, d'autant plus que le fondateur du Collège Sainte-Marie et de ses Archives, le père Félix Martin, fut un grand admirateur de l'architecture médiévale et de l'art de l'enluminure, tel qu'en témoignent trois de ses carnets de croquis qui nous sont parvenus. Nous chercherons donc, dans le cadre de cette enquête, les preuves d'un intérêt partagé pour les Heures de Philippe de Montholon et le manuscrit MS-1 In- $12^{\circ}$, en explorant les papiers des successeurs du père Martin à la direction des Archives du Collège Sainte-Marie, parmi lesquels le père Arthur Edward Jones demeura une figure dominante de 1882 à $1918^{14}$.

14. La provenance des deux livres d'Heures fut pendant longtemps associée à la famille fribourgeoise d'Odet d'Orsonnens, dont le jésuite Jean-Ivan d'Orsonnens (1875-1956), entré dans la Compagnie de Jésus le 18 mars 1895, était issu. Or, un examen approfondi des archives personnelles du père d'Orsonnens, conservées aux Archives des jésuites au Canada, ne permet pas de soutenir une telle hypothèse quant à la provenance des deux manuscrits enluminés. L'hypothèse ne résiste pas, en effet, à l'examen de la documentation. Elle tirait sans doute son origine de la grande ancienneté des documents que le père d'Orsonnens confia ou légua en très grand nombre aux Archives du Collège Sainte-Marie dans les années 1940 et 1950. D’ailleurs, les documents les plus anciens conservés aux Archives des jésuites au Canada se trouvent pour la plupart dans le Fonds Jean-Ivan d'Orsonnens (Fonds BO-0075). Des livres du XVI e siècle ayant appartenu à la famille d'Odet d'Orsonnens, dont l'un porte l'ex-libris du Collège Sainte-Marie, sont conservés aujourd'hui à l'Université du Québec à Montréal. Voir Brenda Dunn-Lardeau, dir., Catalogue des imprimés des XV et XVI siècle dans les collections de l'Université du Québec à Montréal (Presses de l'Université du Québec, 2013), 110, 238, 299. 


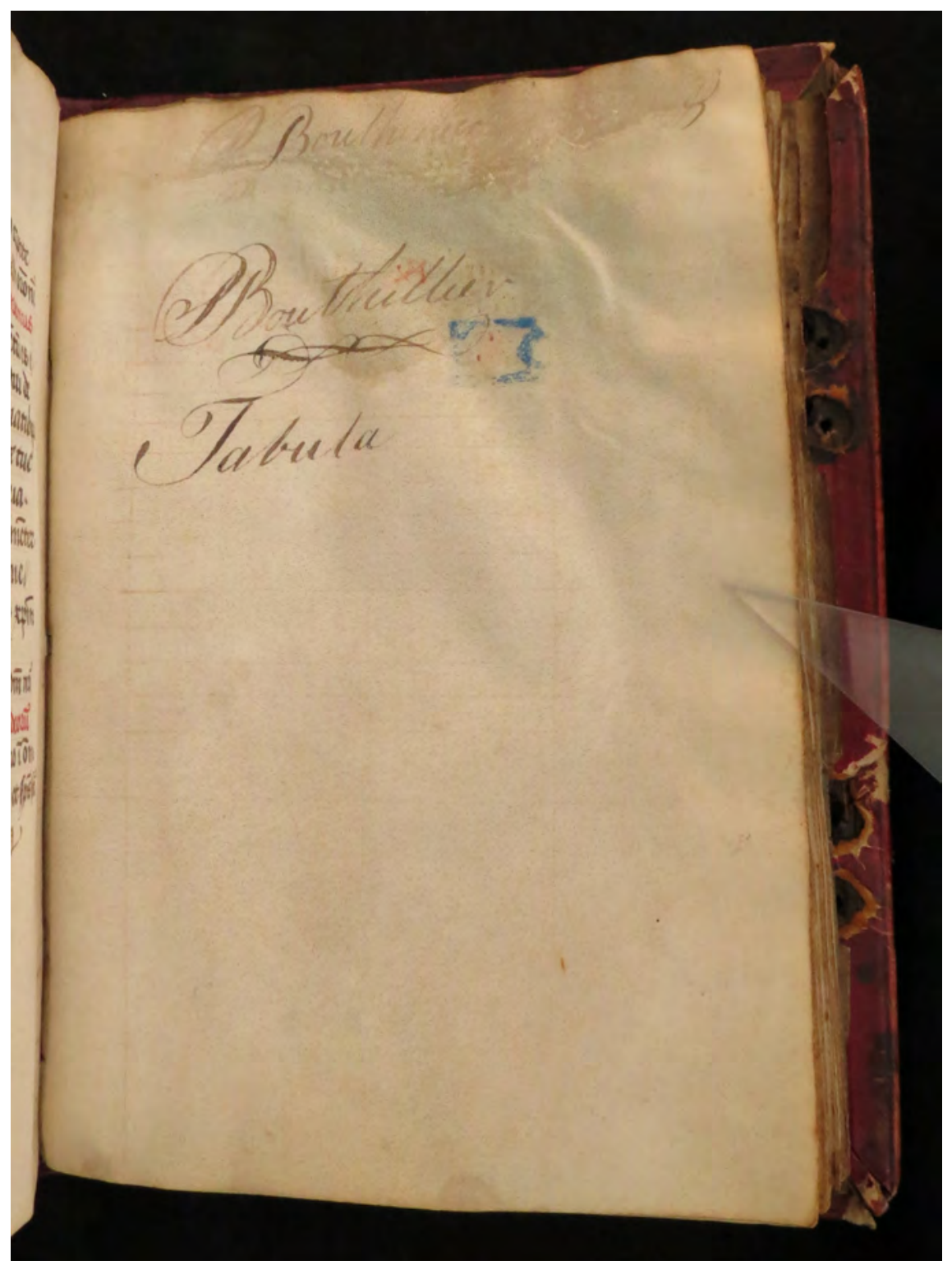

Fig. 1. Inscriptions manuscrites : «P Bouthillier », «PBouthillier » et « Tabula ». Manuscrit MS-1 In-12 ${ }^{\circ}$. Archives des jésuites au Canada / The Archive of the Jesuits in Canada, 0900-0010.2.1. 


\section{Les livrets de dévotion, livres d'Heures et livres-reliques dans les Relations des jésuites}

Dans les Relations de 1653-1654 et 1664-1665 du père François-Joseph Le Mercier, imprimées à Paris en 1655 et 1666, un Nouveau Testament, un petit livret de dévotion et un livre d'Heures prirent valeur de reliques, au regard des circonstances dramatiques et sanctifiantes auxquelles ils étaient associés.

François-Joseph Le Mercier rapportait en effet, dans sa Relation de ce qui s’est passé en la Mission des Peres de la Compagnie de Jesus, au païs de la Nouvelle France, depuis l'esté de l'année 1653. jusqu'à l'esté de l'année 1654, combien le jésuite Simon Le Moyne s'était ému de mettre la main sur deux livres qu'il savait être les " aimables reliques " des pères Jean de Brébeuf et Charles Garnier ${ }^{15}$. François-Joseph Le Mercier précisait, à l'intention du Provincial Nicolas Royon, destinataire de la Relation, qu'il racontait le « [v]oyage du Pere Simon Le Moine dans le païs des Iroquois Onnontaehronnons en Juillet, Aoust, \& Septembre [1654] » en suivant le journal de ce dernier ${ }^{16}$. Le récit proposé par Simon Le Moyne mettait en évidence la nécessité impérieuse de préserver les deux livres repris aux Iroquois :

Je recouvray de la main d'un de ces barbares, le nouveau testament du feu Pere Jean de Brebeuf, qu'ils ont fait mourir cruellement, il y a cinq ans, \& un autre petit livret de devotion qui avoit servy au feu Pere Charles Garnier, qu'ils ont eux-mesme tué, il y a quatre ans ; Ces deux Peres estoient en leur Mission, lorsque cette heureuse mort leur arriva, pour recompense des travaux de plusieurs années, qu'ils avoient saintement employées en toutes ces contrées. Pour moy, qui suis tesmoin de la sainteté de leur vie, \& de la gloire de leur mort, je feray plus d'estat toute ma vie de ces deux petits livrets, leurs aimables reliques, que si j'avois rencontré quelque mine d'or, ou d'argent ${ }^{17}$.

15. Lucien Campeau, éd., Monumenta Novæe Franciøe, 9 vols. (Rome, Montréal : Institutum Historicum Soc. Iesu, Les Éditions Bellarmin, 1996), vol. VIII : doc. 139, ch. VII, \$34, 697-698 et Thwaites, The Jesuit Relations, vol. 41 : doc. LXXXVI, 118-120.

16. Thwaites, The Jesuit Relations, vol. 41 : doc. LXXXVI, 90.

17. Campeau, Monumenta Novee Francie, vol. VIII : doc. 139, ch. VII, $\$ 34,697-698$ et Thwaites, The Jesuit Relations, vol. 41 : doc. LXXXVI, 118-120. C'est l'auteur qui souligne. 
Notre première curiosité serait évidemment de savoir en quels lieux et pendant combien d'années, décennies ou siècles, ces livres-reliques sont passés de main en main, bien qu'il nous faille convenir aujourd'hui de leur improbable survie.

Dans une relation subséquente, publiée au cours de la décennie suivante, le père François-Joseph Le Mercier fit allusion à un autre livre de dévotion, plus précisément à un livre d'Heures qui aurait appartenu à un certain René. Cependant, il ne manifesta pas au premier chef un souci de préservation semblable à celui qu'il avait exprimé dans sa Relation de 1653-1654 à propos du Nouveau Testament de Jean de Brébeuf et du livret de dévotion de Charles Garnier. En effet, dans la Relation de ce qui s'est passé en la Nouvelle France, és années 1664. \& 1665, le père Le Mercier s'attacha plutôt à souligner l'authenticité du récit rapporté, en présentant d'abord la lettre dans laquelle étaient décrites les cruautés que des Iroquois avaient infligées à quelques Français qu'ils avaient faits prisonniers en août 1662 :

Voicy une lettre qui nous est tombée entre les mains, touchant le cruel traitement, que quelques François ont receû des Iroquois, depuis deux ans, \& dont nous n'avions pas encore de connoissance.

Je ne change rien, ni aux paroles, ni au stile de la lettre ; parce que sa simplicité trouvera plus de creance dans les esprits.

(Thwaites, The Jesuit Relations, vol. 50 : doc. CXVII, 54)

$\mathrm{Au}$ terme de rudes affrontements, une fois qu'ils furent soumis aux violences de leurs ennemis, deux des prisonniers français - nommés René et monsieur Brignac - avaient cheminé pendant huit jours avec les Iroquois de la Nation d'Onnejout, avant que ceux-ci se réunissent et se retrouvent « au mesme cabanage " que les Iroquois de la Nation d'Annigué, où ils ont fait "grande réjouïssance, \& grande chere de leur chasse » (Thwaites, The Jesuit Relations, vol. 50 : doc. CXVII, 58). Malgré leurs souffrances, ou précisément à cause d'elles, les captifs priaient. Les signes extérieurs de leur recueillement suscitèrent à deux occasions des échanges entre lesquels le contraste est frappant. Une première scène, somme toute émouvante, montrait René attaché à un arbre et priant tout bas. Un Iroquois, qui l'avait aperçu, lui demanda ce qu'il faisait. René répondit qu'il priait Dieu. L'autre le libéra alors de ses liens et lui dit : « Prie à ton aise, mets toy à genoux » (Thwaites, The Jesuit Relations, vol. 50 : doc. CXVII, 56). 
Dans un passage subséquent du récit, moins rassurant celui-là, le narrateur laissa entendre que René avait échappé de peu au châtiment qu'avait failli lui valoir la lecture de son livre d'Heures : « [1]es Iroquois s'estant apperceus que René avoit des heures, \& qu'il lisoit dedans, luy voulurent couper un poulce, \& luy deffendirent de frequenter davantage le Sieur Brignac, à cause qu' ils prioient Dieu ensemble» (Thwaites, The Jesuit Relations, vol. 50 : doc. CXVII, 58).

Ces Heures, de même que le petit livret de dévotion du martyr Charles Garnier, étaient-elles manuscrites ou imprimées? À dire vrai, la question appelle une réflexion plus large sur la présence et le sort des manuscrits - enluminés ou non - dans la Nouvelle-France du XVII ${ }^{e}$ siècle, étant donné la présence avérée de livres d'Heures dans la colonie. Heures et livres de dévotion furent $\mathrm{du}$ reste réclamés régulièrement par la deuxième Supérieure des religieuses hospitalières de Québec, Marie de Saint-Bonaventure-de-Jésus, auprès de bienfaiteurs européens, tel que dans ses lettres et requêtes jointes aux Relations parues à Paris dans la deuxième moitié du XVII e siècle (soit les Relations de 1664-1665, 1665-1666, 1666-1667 et 1667-1668).

Sa lettre du 23 octobre 1665, publiée l'année suivante par Sébastien Cramoisy et Sébastien Mabre-Cramoisy, avec la Relation de 1664-1665 du père François-Joseph Le Mercier, était suivie d'un « Estat et memoire des besoins, \& choses necessaires dont les pauvres filles religieuses de l'Hospital de Kebec en la Nouvelle France, ont grande disette pour subvenir au soulagement des pauvres malades qui y sont à present en grand nombre » (Thwaites, The Jesuit Relations, vol. 49 : doc. CXVII, 204). La liste des choses requises comprenait, parmi d'autres : " [t]rois livres de Rheubarbe ", "[h] uit onces d'huile de Camomille ", deux livres de "Canelle », de "Cloud de Girofle » et de " Muscade », « [d]ix livres de Cierges ou bougie blanche ou jaune pour dire la Messe à l'Hospital », $\mathrm{du}$ «Sucre fin \& de la Cassonnade », « [t] rois livres de Diachilon », « [q] uatre livres de bonne Reglisse ", du "Caffe de Montpellier», un "petit mortier de fonte pour dissoudre les Medecines ", des draps, de " la toile pour ensevelir les morts ", des " couvertures bleuës \& vertes", des «bonnets de laine pour hommes \& pour femmes ", "[h]uit pots de chambre ", trente-six écuelles et " saucieres de portion », vingt-quatre tasses, quatre grands plats, « [q] uarantehuit cueillieres », des épingles, des « éguilles » et des « dez à coudre », « [q] uatre rames de papier à écrire ", etc. (Thwaites, The Jesuit Relations, vol. 49 : doc. CXVII, 204, 206, 208, 210). Choses utiles auxquelles étaient ajoutés, en fin de liste, les précieux articles de la vie spirituelle : 
Des Heures de la Vierge.

Le Livre du P. Chiffletius ${ }^{18}$.

Journée Chrestienne de Monsieur Olier de S. Sulpice ${ }^{19}$.

Conduite de Monsieur de Sales ${ }^{20}$.

Exercice de la presence de Dieu ${ }^{21}$.

Autres Livres de devotion, de diverses sortes.

Des Chapelets.

Des Images.

(Thwaites, The Jesuit Relations, vol. 49 : doc. CXVII, 210)

Les derniers biens réclamés en 1666 dans le Memoire des choses necessaires pour le soulagement des pauvres malades de l'Hospital de Kebec, publié l'année suivante à la suite de la Relation de 1665-1666 du père Le Mercier, se présentaient comme suit :

Un Messel Romain des derniers imprimez, avec le Propre des Saints de l'Ordre de saint Augustin,

Des petites Heures pour prier Dieu, \& d'autres petits Livres de devotion,

Des Chapelets.

(Thwaites, The Jesuit Relations, vol. 50 : doc. CXVIII, 162)

Dans le mémoire accompagnant sa lettre du 20 octobre 1667, Marie de Saint-Bonaventure-de-Jésus maintenait la demande d'envoi de « Chappelets » et de «petits Livres de Devotion », qu'elle allait réitérer à la même date l'année

18. Le jésuite Pierre-François Chifflet (1592-1682) avait publié à Dole, en 1629, le manuel de spiritualité Practique journalière de l'Amour de Dieu par forme d'oblation de soy mesme: avec une formule des actes de la vraye dévotion à la Très-sacrée Vierge Mere de Dieu; aussi appropriée aux anges et aux saincts (Dole : Antoine Binard, 1629). Le père Chifflet fut attaché au Collège des jésuites de Dijon de 1645 à 1675. Voir Laurence Delobette et Paul Delsalle, dir., Autour des Chifflet : aux origines de lérudition en Franche-Comté. Actes des journées d’étude du Groupe Chifflet (Besançon : Presses universitaires de Franche-Comté, 2007), 142.

19. La Journée chrestienne fut publiée la première fois en 1655 sous le titre La Journée chrestienne, par un prêtre du clergé. Ce n'est qu'à partir de 1657 que le nom de l'auteur, Jean-Jacques Olier, fut mentionné.

20. Cette «Conduite» renvoie certainement à l'Introduction à la vie dévote (1608) de François de Sales. 21. Il semblerait s’agir de l'Exercice de la presence de Dieu du jésuite François Arias, publié en 1607. 
suivante (Thwaites, The Jesuit Relations, vol. 51 : doc. CXXI, 114 ; vol. 52 : doc. CXXIV, 108).

Dans tous les cas, une consigne était donnée quant à l'acheminement des dons, laquelle ramenait au premier plan la vaste entreprise éditoriale dont était tributaire cette demande d'assistance matérielle. La Supérieure des religieuses hospitalières de Québec ajoutait toujours en effet, au sujet de la cueillette des aumônes consenties au Nouveau Monde, et en ces mots (à quelques nuances près) :

Messieurs et Dames qui auront la bonté de faire quelques charitez \& aumosnes des Drogues \& autres choses specifiées au Memoire cy-apres escrit, sont priez de les envoyer chez Monsieur Cramoisy Imprimeur ordinaire du Roy, Bourgeois de Paris demeurant ruë S. Jacques, ou de l'en faire avertir, \& il ne manquera de les envoyer querir.

(Thwaites, The Jesuit Relations, vol. 50 : doc. CXVIII, 158-160).

Un pont avait été jeté entre deux continents par Sébastien Cramoisy, avec la publication, en Europe, des Relations des jésuites de la Nouvelle-France, amorcée dès 1632. Les traces explicites de dons de livres que l'imprimeur avait lui-même fait parvenir aux missionnaires de la colonie subsistent d'ailleurs aujourd'hui, la marque manuscrite "Ex dono Sebastiani Cramoisy " étant toujours bien lisible dans quelques exemplaires survivants de la bibliothèque du Collège de Québec fondé par les jésuites en 1632-1635 (fig. 2) 22, à l'instar des ex-libris et ex-dono de communautés religieuses ou de particuliers qui donnèrent également des livres à l'institution.

22. L’ex-dono a été repéré dans au moins trois ouvrages imprimés par Sébastien Cramoisy en 1631 et 1636 : deux des trois exemplaires en question sont conservés à la Bibliothèque de la Compagnie de Jésus du Collège Jean-de-Brébeuf ; l'autre exemplaire se trouve à la Bibliothèque des livres rares et collections spéciales de l'Université de Montréal. Pour plus de détails sur cette question, voir Johanne Biron, « Les ex-libris, ex-dono, lettres et notes manuscrites, ces témoins de l'unité et de la dispersion des collections des jésuites du Québec ", in Marc André Bernier, Johanne Biron et Claude La Charité, dir., Mémoires du livre (Le patrimoine lettré et les imprimés anciens au Québec et au Canada. Travaux pour une histoire du livre, des collections et de la lecture) 5.1 (automne 2013) : $\$ 18$ et n. 44, http://www.erudit.org/revue/ memoires/2013/v5/n1/index.html. 


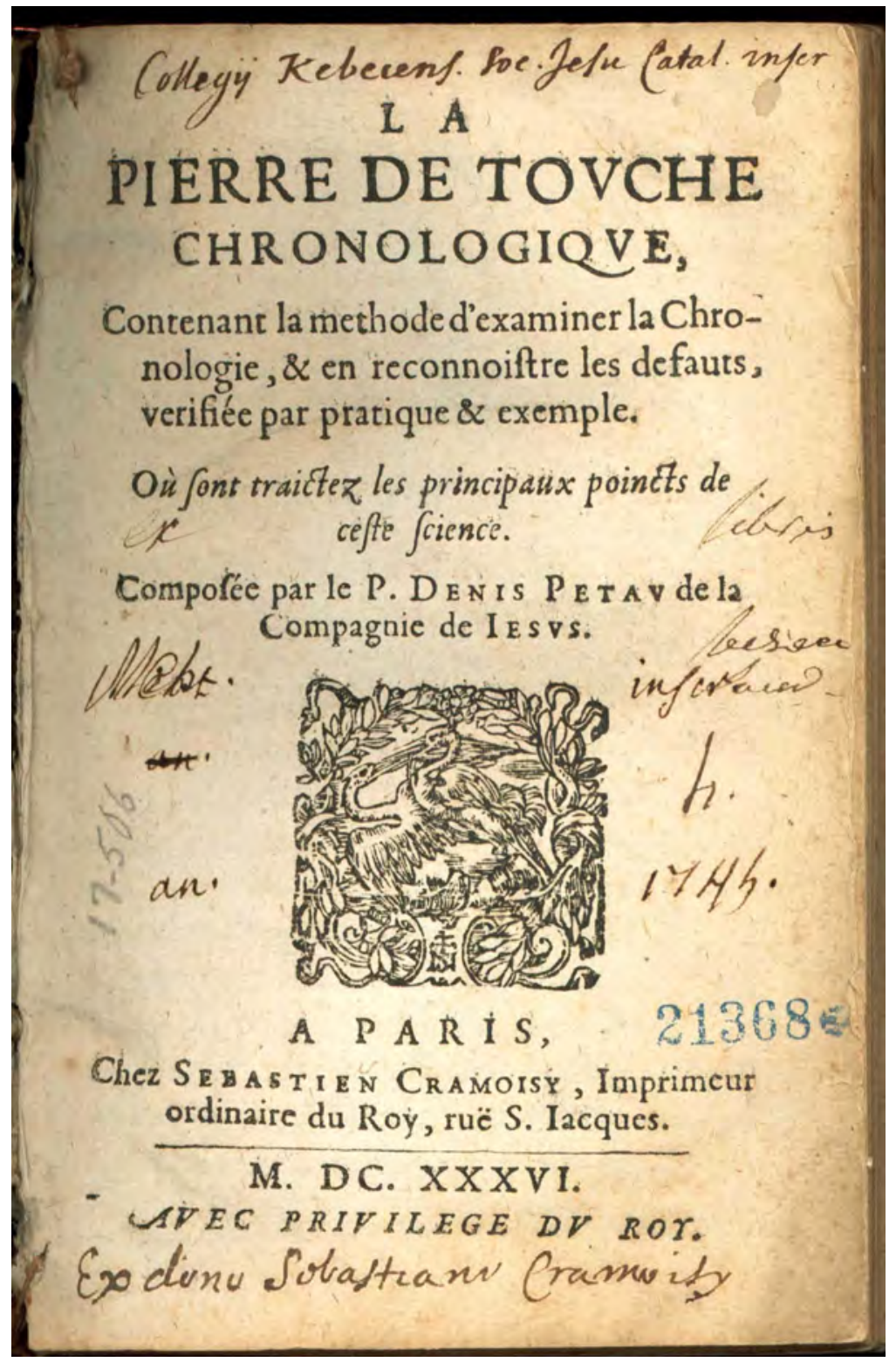

Fig. 2. Ex-dono de Sébastien Cramoisy. Page de titre de La Pierre de touche chronologique du père Denis Petau (Paris : Sébastien Cramoisy, 1636). Bibliothèque de la Compagnie de Jésus. Cliché IMAQ, BCJ 36009. 


\title{
2. Quelques remarques sur la provenance des Heures de Philippe de Montholon
}

En retour, un témoignage d'outre-Atlantique exaltant les largesses des ursulines de Dijon à l'endroit des missions du Canada nous semble offrir une percée dans le mystère qui entoure la présence au Québec des Heures de Philippe de Montholon (MS-009-in- $8^{\circ}$ ), car c'est dans les pages liminaires de la Vie de madame Catherine de Montholon, veuve de monsieur de Sanzelles, maistre des requestes, et fondatrice des Ursulines de Dijon ${ }^{23}$ publiée en 1653, trois ans après la mort de Catherine de Montholon, que son auteur, Jean-François Senault, prêtre de l'Oratoire de Jésus, adressait ces louanges aux religieuses ursulines de Dijon :

\begin{abstract}
Vous assistez de vos aumosnes les pauvres honteux; sans rompre vostre clausture, vous les allez chercher dans la ville \& dans la campagne ; Et comme si la France n'estoit pas assez grande pour renfermer vos liberalitez, vous passez les mers, \& vous envoyez jusques en Canada des sommes notables, pour ayder les jeunes filles que l'on instruit à notre Religion ${ }^{24}$.
\end{abstract}

Or, l'arrière-grand-père paternel de Catherine de Montholon qui se prénommait Nicolas (voir fig. 3$)^{25}$ eut, de son second mariage avec Marguerite

23. Après la mort de son mari, Catherine de Montholon s'intéressa aux religieuses ursulines de Dijon, elle les soutint matériellement et décida de se retirer dans leur monastère, où elle vécut en retraite pendant plus de trois décennies, jusquà son décès, le 29 avril 1650. Voir Henry Ronot, Richard et Jean Tassel : peintres à Langres au XVII e siècle (Paris : Nouvelles Éditions latines, 1990), 27-30.

24. Père Jean-François Senault, "Aux Reverendes Meres les Religieuses Ursulines du Monastere de Dijon ", in La Vie de madame Catherine de Montholon, veuve de monsieur de Sanzelles, maistre des requestes, et fondatrice des Ursulines de Dijon (Paris : Pierre Le Petit \& Jacques Camusat, 1653), fol. 5vº. 25. « Nicolas de Montholon, II. du nom » eut de sa première femme un fils prénommé François, qui fut fait garde des Sceaux de France en 1542. L’un des fils de ce dernier, également prénommé François, devint garde des Sceaux de France à son tour, en 1588. Catherine était la fille de ce "François de Montholon, II. du nom », et de Geneviève Chartier (M. [François-Alexandre Aubert] de La ChenayeDesbois, "Montholon ", Dictionnaire de la noblesse, contenant les généalogies, l'histoire \& la chronologie des familles nobles de France, lexplication de leurs armes, \& l'état des grandes terres du Royaume aujourd'hui possédées à titre de Principautés, Duchés, Marquisats, Comtés, Vicomtés, Baronnies, ¿̛c. par création, héritages, alliances, donations, substitutions, mutations, achats ou autrement, seconde édition, 15 vols. [Paris : Antoine Boudet, 1775], X : 371-373). Voir aussi Louis Moréri, « Montholon », Le grand 
du May, un fils prénommé Lazare. Ce dernier était le père de Philippe de Montholon (voir fig. 4) ${ }^{26}$, auquel ont appartenu les Heures du même nom conservées aux Archives des jésuites au Canada, tel qu'en font foi les renseignements généalogiques consignés par le propriétaire sur l'avant-dernier feuillet du manuscrit :

Moi, Philippe de Montholon, suis né le $30^{\mathrm{e}}$ jour du mois d'août, à la première heure après minuit, en l'année du Seigneur 1522, dans le lieu appelé Bongdiet, distant de quatre ou cinq mille pas de Chalon, mon père étant Lazare de Montholon, alors avocat royal à la cour de Chalon puis conseiller à Dijon ; mon grand-père paternel étant Nicolas de Montholon, avocat royal à la très haute cour ; ma grand-mère paternelle Marguerite du May $[\ldots]^{27}$.

Une pochette protectrice et un écrin de papier annoté, conçu pour protéger un petit bout de feuillet volant, se trouvent sous le plat supérieur des Heures de Philippe de Montholon. Ils permirent, au fil des ans, d'assurer la conservation d'une ancienne note explicative et de sa transcription, auxquelles fut ajouté un carton complémentaire sur lequel figure cette notice, de la main du père Arthur Edward Jones :

Ces Heures de Feste ont appartenu à

Maître Philippe de Montholon, conseiller

du Roy et député lieutenant général au

baillage de Chalon-sur-Saône

1522-après 1563.

dictionnaire historique, ou, le mélange curieux de l'histoire sacrée et profane, nouvelle édition, dans laquelle on a refondu les supplémens de M. l'Abbé Goujet, le tout revu, corrigé \& augmenté par M. Drouet, 10 vols. (Paris : Les Libraires associés, 1759), VII : 728-729.

26. Voir Moréri, «Fyot de La Marche (Claude) », Le grand dictionnaire historique, V : 420 ; M. de La Chenaye-Desbois, « Montholon », Dictionnaire de la noblesse, 372.

27. Pour la transcription du texte original, voir les documents glissés sous le plat supérieur des Heures de Philippe de Montholon, dont se sont inspirés Patrice Hamel et Guillaume Simard pour réaliser la présente traduction (Hamel et Simard, «Les Heures de Philippe de Montholon», \$ 57). 
Ces informations sont accompagnées d'autres renseignements, dont la fonction était précisément de relayer les précédentes, puisqu'ils publiaient le nom d'un autre possesseur du manuscrit, Jean Fyot, gendre de Philippe de Montholon. La transcription de la note ancienne, qui court sur quelques lignes, s'amorce ainsi : "Appartenant à $S^{\underline{r}}$ Jehan Fagot (sic), [...] Mary de Damoiselle Gasparde de Monthelon, fille, et heritière universelle dudit $S^{\underline{r}}$ de Monthelon [...] ». Sixième enfant de la famille, née en 1559, Gasparde de Montholon était la fille de Philippe de Montholon et de Madeleine Dalmonde ${ }^{28}$, et, faut-il le préciser, " héritière d'une branche de la Maison des deux Gardes des Sceaux de France de ce nom ${ }^{29}$. De son union avec Jean Fyot de La Marche naquirent une fille, Marguerite Fyot, et un fils, Philippe Fyot, dont le propre fils, Claude, né en 1630, soutint avant l'âge de vingt ans des thèses de théologie au Collège des jésuites de Dijon, en présence du roi Louis XIV, auquel ces thèses étaient dédiées (voir fig. 5) ${ }^{30}$.

Compte tenu de ces deux lignages issus de Nicolas II de Montholon, Claude Fyot de La Marche, arrière-petit-fils et petit-fils de deux des propriétaires connus des Heures (descendant donc du second mariage de Nicolas II de Montholon), posséda-t-il le manuscrit enluminé de ses ancêtres? Ou les Heures de Philippe de Montholon passèrent-elles entre les mains de sa parente (issue du premier mariage de Nicolas II de Montholon), Catherine de Montholon, qui « disoit son chapelet trois fois la semaine » et « les Heures de la Vierge les Festes $\&$ les Dimanches ${ }^{31}$, selon son biographe?

28. Dans un Inventaire de chartes, manuscrits, documents historiques sur la Bourgogne faisant partie d'une collection particulière publié en 1886, était recensé ce document de 1578 : « Partage de biens, entre Jean Fyot, conseiller du roi au Parlement de Bourgogne, époux de Gasparde de Montholon, fille du lieutenant général au bailliage de Chalon et Philippine de Montholon, pour les biens venant de Magdelaine d'Almonde, leur mère, etc. " (Mémoires de la Société bourgignonne de géographie et d'histoire [Dijon : Imprimerie Darantière, 1886], IV : 29).

29. M. de La Chenaye-Desbois, « Fyot de La Marche », Dictionnaire de la noblesse, VI : 747. Voir Hamel et Simard, «Les Heures de Philippe de Montholon », $\$ 12$.

30. Moréri, «Fyot de La Marche (Claude) », Le grand dictionnaire historique, V : 420.

31. Père Senault, 85. 
Nicolas II de Montholon

Grand-père de Philippe de

Montholon, qui est le descendant

d'un second mariage

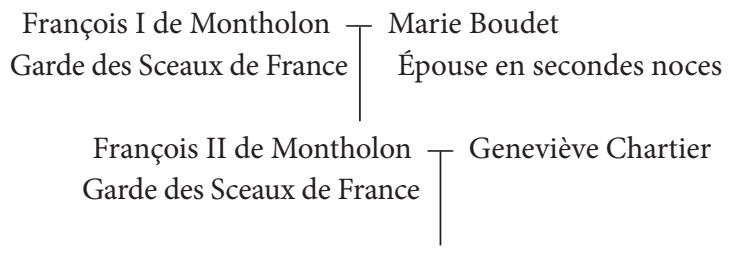

Catherine de Montholon - Monsieur de Sanzelles Bienfaitrice des ursulines de Dijon

Fig. 3. Ancêtres de Catherine de Montholon issus du premier mariage de Nicolas II de Montholon et de Jeanne Chappet.

$$
\begin{aligned}
& \text { Nicolas II de Montholon - Marguerite du May } \\
& \text { Épouse en secondes noces } \\
& \text { Lazare de Montholon }\rceil \text { Jeanne [nom de famille inconnu] } \\
& \text { Philippe de Montholon — Madeleine Dalmonde }
\end{aligned}
$$

Fig. 4. Ancêtres de Philippe de Montholon issus du second mariage de Nicolas II de Montholon et de Marguerite du May.

$$
\begin{gathered}
\text { Jean Fyot de La Marche }\left\lceil\begin{array}{l}
\text { Gasparde de Montholon } \\
\text { Fille de Philippe de Montholon }
\end{array}\right. \\
\text { Philippe Fyot de La Marche } T \text { Claire Guillaume } \\
\text { Claude Fyot de La Marche } \\
\text { Élève du Collège des jésuites de Dijon }
\end{gathered}
$$

Fig. 5. Ancêtres de Claude Fyot de La Marche (connu sous le nom de «l'Abbé Fyot»). 
Catherine de Montholon vécut pendant trente-quatre ans au monastère des religieuses ursulines de Dijon, en gérant son appui matériel à la communauté, dont elle fut la bienfaitrice à plus d'un égard ${ }^{32}$. L’ancien élève des jésuites, Claude Fyot de La Marche, devint aumônier ordinaire du roi en 1651, puis abbé titulaire de l'église abbatiale et collégiale de Saint-Étienne de Dijon en 1662. Il mourut dans cette même ville en $1721^{33}$. Leur attachement à deux familles religieuses dijonnaises - ursuline et jésuite - qui avaient également leurs assises en Nouvelle-France aurait-il pu motiver l'envoi en Amérique des Heures de leur ancêtre, Philippe de Montholon, s'ils en avaient été les possesseurs ? Nous le croyons. Du moins, l'idée plaît-elle à l'esprit. Et elle paraît d'autant plus défendable que les remerciements adressés par Marie de l'Incarnation, depuis Québec, à une Supérieure des ursulines de Dijon, dans une lettre datée du 7 août 1644 , nous encouragent à penser en ce sens :

Nos séminaristes sont très-bien, et elles chantent continuellement des saluts pour leurs bienfaiteurs. Vous êtes du nombre, ma très-honorée Mère, et je vous rends grâces de tout mon cœur de tout ce qu'il vous a plu nous envoyer pour elles et pour ceux qui sont presque continuellement à notre grille ${ }^{34}$.

La seconde Supérieure des religieuses hospitalières de l'Hôtel-Dieu de Québec, Marie de Saint-Bonaventure-de-Jésus, n’en espérerait pas moins de la générosité des bienfaiteurs européens, au cours des décennies suivantes, quand elle solliciterait l'envoi dans la colonie, parmi tant d'autres choses nécessaires, de livres d'Heures et de dévotion. Les religieuses hospitalières assurèrent-elles plus tard la sauvegarde de livres d'Heures enluminés, qu'elles auraient conservés avec les manuscrits des jésuites de la Nouvelle-France que leur avait confiés le père Jean-Joseph Casot? Un fait est sûr : elles furent les braves gardiennes d'un

32. Voir Ronot, 27-30.

33. Voir Moréri, «Fyot de La Marche (Claude) », Le grand dictionnaire historique, V : 420 et M. l'Abbé Papillon, "Claude Fyot de La Marche », Bibliothèque des auteurs de Bourgogne (Dijon : François Desventes, 1745), I : 233.

34. L’Abbé Richaudeau, éd., Lettres de la Révérende Mère Marie de l'Incarnation (née Marie Guyard) : première Supérieure du monastère des ursulines de Québec, 2 vols. (Paris, Leipzig, Tournai : Librairie internationale catholique, L. A. Kittler, Vve H. Casterman, 1876), I : lettre LV, 194-195. 
précieux patrimoine manuscrit, de la fin du XVIII ${ }^{e}$ siècle jusqu'au rétablissement de la Compagnie de Jésus au Canada, en 1842.

\section{Deux livres d'Heures enluminés exposés au Canada et aux États-Unis parmi les manuscrits des premiers missionnaires jésuites de la Nouvelle-France}

Une exposition organisée en 1897, à l'occasion de la réouverture de la bibliothèque du Catholic Club de New York, mit à l'honneur les manuscrits des premiers missionnaires jésuites en Amérique du Nord conservés au Collège Sainte-Marie, avec ce libellé explicite du catalogue : Exhibit of Manuscripts of the Early Jesuit Missionaries in North America from St. Mary's College, Montreal, at the Catholic Club, New York, on the Occasion of the Reopening of the Library. Dans ce catalogue publié en 1897 - mais également dans les catalogues d'autres expositions organisées au Canada et aux États-Unis entre 1892 et 1904, que nous présenterons plus loin - les Heures de Philippe de Montholon (MS-009-in- $8^{\circ}$ ) et le manuscrit MS-1 In- $12^{\circ}$ occupaient le premier rang parmi les manuscrits présentés, compte tenu de leur date de fabrication. Leurs désignations (en anglais "Psalter ", sans doute en souvenir de l'ancêtre des livres d'Heures) correspondaient aux entrées 1 et 2 du catalogue imprimé en 1897 (voir fig. 6 et 7) :

1. 1522 (ante). Illuminated Psalter belonging to the Montholon family.

2. Small illuminated Psalter of the 14th Century ${ }^{35}$.

De toute évidence, l'exposition new-yorkaise de 1897 consacrée aux manuscrits des premiers missionnaires jésuites en Amérique du Nord devait rassembler les manuscrits que ces derniers écrivirent aussi bien que ceux dont ils furent (ou eussent pu être) les propriétaires, les dépositaires.

35. Exhibit of Manuscripts of the Early Jesuit Missionaries in North America from St. Mary's College, Montreal, at the Catholic Club, New York, on the Occasion of the Reopening of the Library (December 9, 1897), 1. 


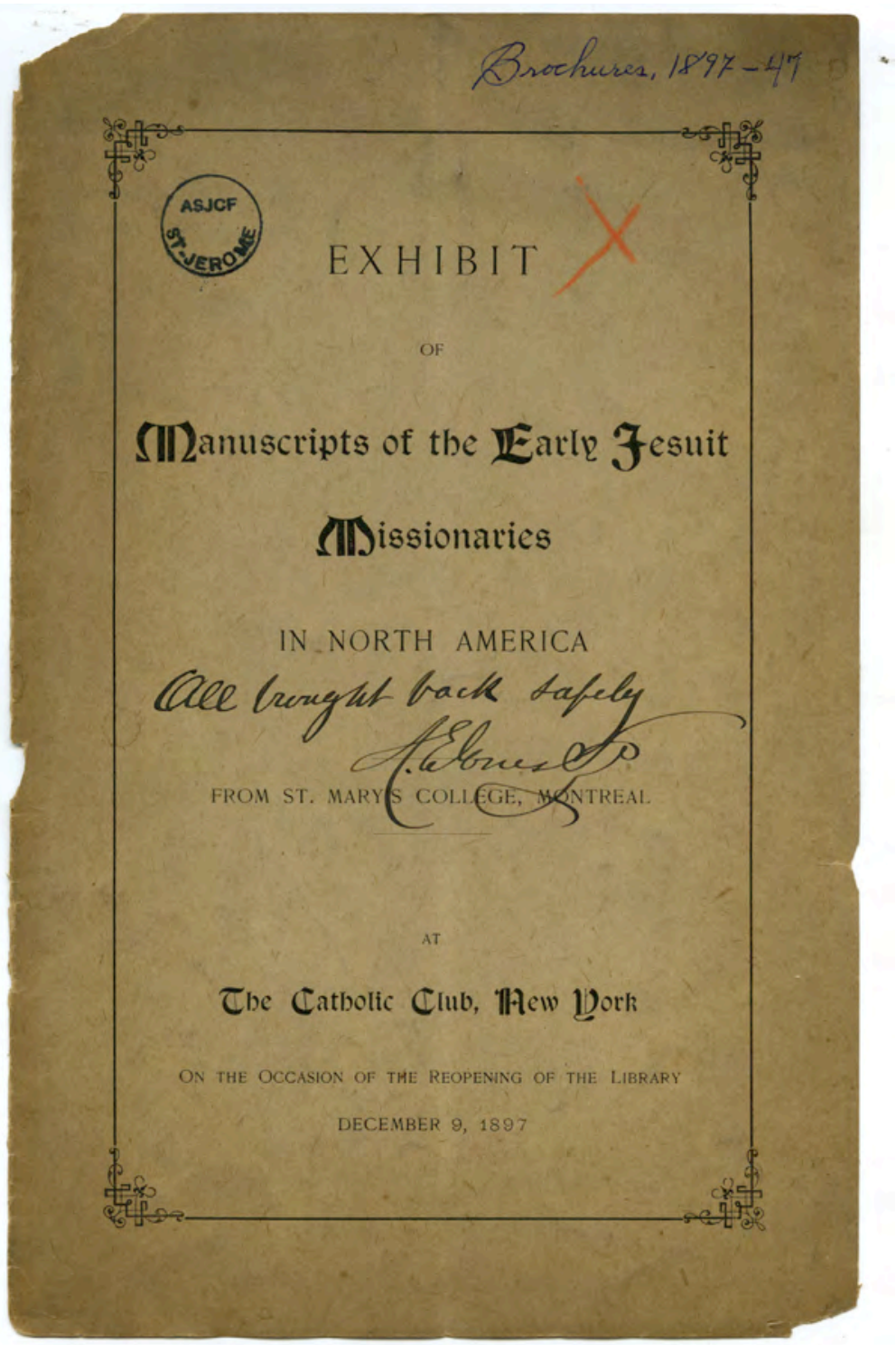

Fig. 6. Couverture du catalogue Exhibit of Manuscripts of the Early Jesuit Missionaries in North America from St. Mary's College, Montreal (New York : 1897). Note autographe du jésuite Arthur Edward Jones : « All brought back safely. A. E. Jones S. J. ». Archives des jésuites au Canada / The Archive of the Jesuits in Canada, Brochures 1897-47. 
E X H I B I T

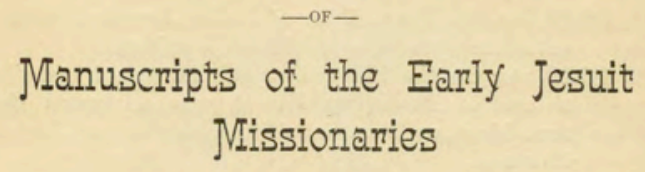

IN NORTH AMERICA.

1. 1522 (ante). Illuminated Pralter belonging to the Montholon family.

2. Small illuminated Psalter of the 14th Century.

3. 1636, April 6. Fac-simile of a Letter from. Father Isaac Jogues to his mother.

4. 1639. Chevalier de Sillery's donation-1, Offieial duplicate; autograph signatures of the Notaries Bergeon and Cousinet; 2, Copy in the handwriting of Father Jean de Quen, the discoverer of Lake St. John ; 3, autograph copy by Gabriel Lalemant, martyred by the Iroquois, March 17, 1649.

5. 1639, July 12 . "Prise de Possession de l'Isle aux Ruaux." Original act. Autograph signatures of Montmagny, the Governor, of Father Charles Raymbaut, \&c.

6. 1638-1649. Contemporaneous copy of Father Charles Garnier's Letters.

7. 1644, Feb. 8. Original Brief of Urbain VIII. in favour of the Huron Chapel of St. Joseph near Old Fort St. Mary's, Simcoe Co., Ontario.

8. 1645, Feb. 20, Paris. Autograph Letter of Father J. Fillean, Provincial of France, to the Sisters of the Hôtel-Dieu, Quebec.

9. 1646, Feb. 20, Rome. Letter of Father Etienne Charlet, French Assistant of the General at Rome, to the same community.

Fig. 7. Catalogue. Exhibit of Manuscripts of the Early Jesuit Missionaries in North America from St. Mary's College, Montreal (New York : 1897), 1. Archives des jésuites au Canada / The Archive of the Jesuits in Canada, Brochures 1897-47. 


\subsection{Le riche héritage du père Félix Martin}

Un demi-siècle plus tôt, en 1848, le père Félix Martin fondait le Collège SainteMarie, dont les Archives avaient été créées à l'automne 1844 pour assurer la sauvegarde des manuscrits originaux de l'ancienne colonie française, parmi lesquels se trouvaient quelque soixante-quinze pièces du XVII ${ }^{e}$ siècle que les religieuses hospitalières avaient eu la générosité de remettre aux jésuites à leur retour au Canada ${ }^{36}$. L'un des plus éminents successeurs du père Martin à la tête des Archives du Collège Sainte-Marie, le père Arthur Edward Jones, écrivait, le 15 avril 1890, en réponse à une demande du père Camille de Rochemonteix, auteur du grand ouvrage à paraître en 1895, Les jésuites et la Nouvelle-France au XVII siècle:

Il faut savoir que nos archives sont de création récente. [...] Les RR. de l'Hôtel-Dieu de Québec ont été dépositaires de plusieurs documents reçus des mains de nos derniers pères. Ces bonnes RR. nous ont rendus (sic) tout ce qu'elles ont pu trouver. Le Père Martin n'a presque pas ajouté à ces trésors, il s'est borné à les publier ${ }^{37}$.

Le père Jones faisait implicitement référence à la publication à Paris, en 1861, d'un ensemble de relations qui étaient demeurées inédites jusque-là. Le père Félix Martin avait en effet préparé, en collaboration avec Fortuné de Montezon, un manuscrit qui fut publié en deux volumes sous le titre de Mission du Canada : relations inédites de la Nouvelle-France (1672-1679) pour faire suite aux anciennes relations (1615-1672), avec deux cartes géographiques ${ }^{38}$. Dans son introduction, le père Martin insistait sur l'esprit dans lequel les Relations publiées en continu de 1632 à 1672 avaient été écrites, de même que sur les raisons qui pouvaient expliquer l'interruption de leur publication après 1673. Il renouait le fil d'une « œuvre si longtemps interrompue $»^{39}$, en se félicitant

36. Voir Desjardins, 32-33.

37. Copie d'une lettre dactylographiée du père Arthur Edward Jones, s.j., envoyée au père Camille de Rochemonteix, s.j., à Rouen, le 15 avril 1890 (AJC. Fonds Arthur Edward Jones, s.j., BO-0035-9, 4). Voir plus haut n. 1 et 10 .

38. Voir Giguère, « Martin, Félix », Dictionnaire biographique du Canada.

39. Félix Martin, s.j., "Introduction », Mission du Canada : relations inédites de la Nouvelle-France (1672-1679) pour faire suite aux anciennes relations (1615-1672), avec deux cartes géographiques, [pub. 
de disposer des matériaux indispensables à la reconstitution des relations postérieures à 1672 :

Ces précieux monuments d'un autre âge, ainsi que plusieurs autres qui viennent de la même source et qui ont le même objet, avaient été laissés à sa mort, par le P. Cazot, Jésuite, comme un témoignage de sa reconnaissance et comme un héritage de vertu aux religieuses de l'Hôtel-Dieu de Québec, où il a rendu le dernier soupir en 1800. C'est des mains de ces vertueuses dames, qui perpétuent si héroïquement jusqu'à nos jours, depuis plus de deux siècles, leur mission de charité et de dévouement, que nous avons reçu avec un religieux respect ce précieux dépôt. Ces feuilles détachées, et pendant longtemps en désordre, ne tardèrent pas à nous offrir un tout complet dont il était facile d'apprécier l'importance ${ }^{40}$.

Au fil des ans, grâce à des achats, des dons, des legs, le père Martin ajouta des livres rares et des manuscrits précieux au don des religieuses ${ }^{41}$. Son retour définitif en France en 1861 n'épuisa pas son intérêt pour l'histoire religieuse de la Nouvelle-France et ses principaux martyrs ; il demanda même qu'après sa mort tous les manuscrits qu'il avait en sa possession fussent envoyés à Montréal ${ }^{42}$.

Les « Papiers du P. Fx. Martin $»^{43}$ conservés aux Archives des jésuites au Canada comprennent trois carnets de croquis qui révèlent la grande maîtrise que le jésuite avait de l'art du dessin, de même que son goût marqué pour

par le P. Martin, s.j.], «Voyages et travaux des missionnaires de la Compagnie de Jésus, publiés par des Pères de la même Compagnie pour servir de complément aux Lettres édifiantes », III, (Paris : Charles Douniol, 1861), 1 : xxvi.

40. Martin, «Introduction », 1 : xxvi-xxvii.

41. Voir Archives des jésuites au Canada, « Historique », consulté le 25 mai 2015, http://archivesjesuites. $\mathrm{ca} / \mathrm{fr} /$ historique/.

42. «[...] tous les manuscrits que j’ai, je veux demander qu’à ma mort ils soient envoyés à Montréal ", (Lettre du père Félix Martin, s.j., au P. Vignon, Collège Sainte-Marie, Montréal, 22 juillet 1861. AJC. Fonds Archives, Collège Sainte-Marie, Q-0001, CACSM 1, dossier 1639 bis, fol. 1vº).

43. Nous reprenons ici la marque de possession estampillée « Papiers du P. Fx. Martin » observée dans plusieurs documents. 
l'architecture médiévale ${ }^{44}$. Il dessina, dans ces carnets reliés, des paysages, des façades d'églises, des monuments, des portions d'édifices, des vues générales de montagnes et de villes, etc., qu'il eut le loisir d'admirer, pour la plupart, sur le continent européen, pendant sa jeunesse et ses années de formation ${ }^{45}$. Ses souvenirs européens, de France, d'Italie, de Suisse, côtoient les paysages canadiens dans le troisième carnet (Croquis - dessins de la main du P. Martin. - Chutes de la Chaudière, près de Québec), dans lequel il s'exerça à l'art de l'enluminure, en s'inspirant d'un «manuscrit du B. Angelico de Fiasolo $^{46}$, mort en 1455 » (voir fig. 8). Au recto du vingt-cinquième feuillet $\mathrm{du}$ carnet, il esquissa des formes propres aux enluminures de l'Annonciation. Autour d'une lettrine ornée, aux couleurs jaune, rouge et bleu, il traça différents ensembles au crayon : l'ange Gabriel agenouillé et portant un phylactère sur lequel étaient suggérées les premières paroles de la salutation angélique («Ave Gr[atia] »), mais aussi des feuilles d'acanthe, représentatives des éléments décoratifs qui ornent les bordures d'enluminures, ainsi que des entrelacs sur le plat d'une reliure, reproduits d'après une reliure du XVI ${ }^{\mathrm{e}}$ siècle, dont une légende rappelait les couleurs. Le père Félix Martin dut avoir sous les yeux le manuscrit du Beato Angelico pour en reprendre ainsi les détails, tels l'ange, les feuilles d'acanthe de la bordure et la lettrine, à savoir la lettre initiale ornée «D » de la formule d'ouverture «Domine labia mea aperies» («Seigneur, ouvre mes lèvres ») des Heures de Matines, qui sont accompagnées des enluminures de l'Annonciation ${ }^{47}$.

44. Nous renvoyons le lecteur intéressé par le contenu de ces trois carnets peu connus à l'excellent article de Jean-Sébastien Sauvé, "Les carnets de croquis du père jésuite Félix Martin (1804-1886) », Journal de la société pour létude de l'architecture au Canada 39.1 (2014) : 35-55. Le père Félix Martin demeure, selon l'auteur, « un précurseur méconnu de l'étude de l'architecture médiévale » (54).

45. Voir Sauvé, 35-55. Entre autres disciplines, le père Martin enseigna le dessin, l'architecture et la géométrie au Collège Sainte-Marie, où il fut le professeur de dessin du jeune Arthur Edward Jones, à qui il enseigna les éléments de l'architecture, les techniques pour la levée des plans, etc., alors que ce dernier y était élève. Voir les notes dactylographiées du père Arthur Melançon, « P. Arthur E. Jones, S.J. ", 2 (AJC. Fonds Arthur Edward Jones, s.j., BO-0035-1, 29(13)).

46. Fra Angelico de Fiesole, ou Beato Angelico (vers 1400-1455).

47. Nous remercions Brenda Dunn-Lardeau pour les remarques qu’elle nous a généreusement transmises à propos de ce feuillet. 

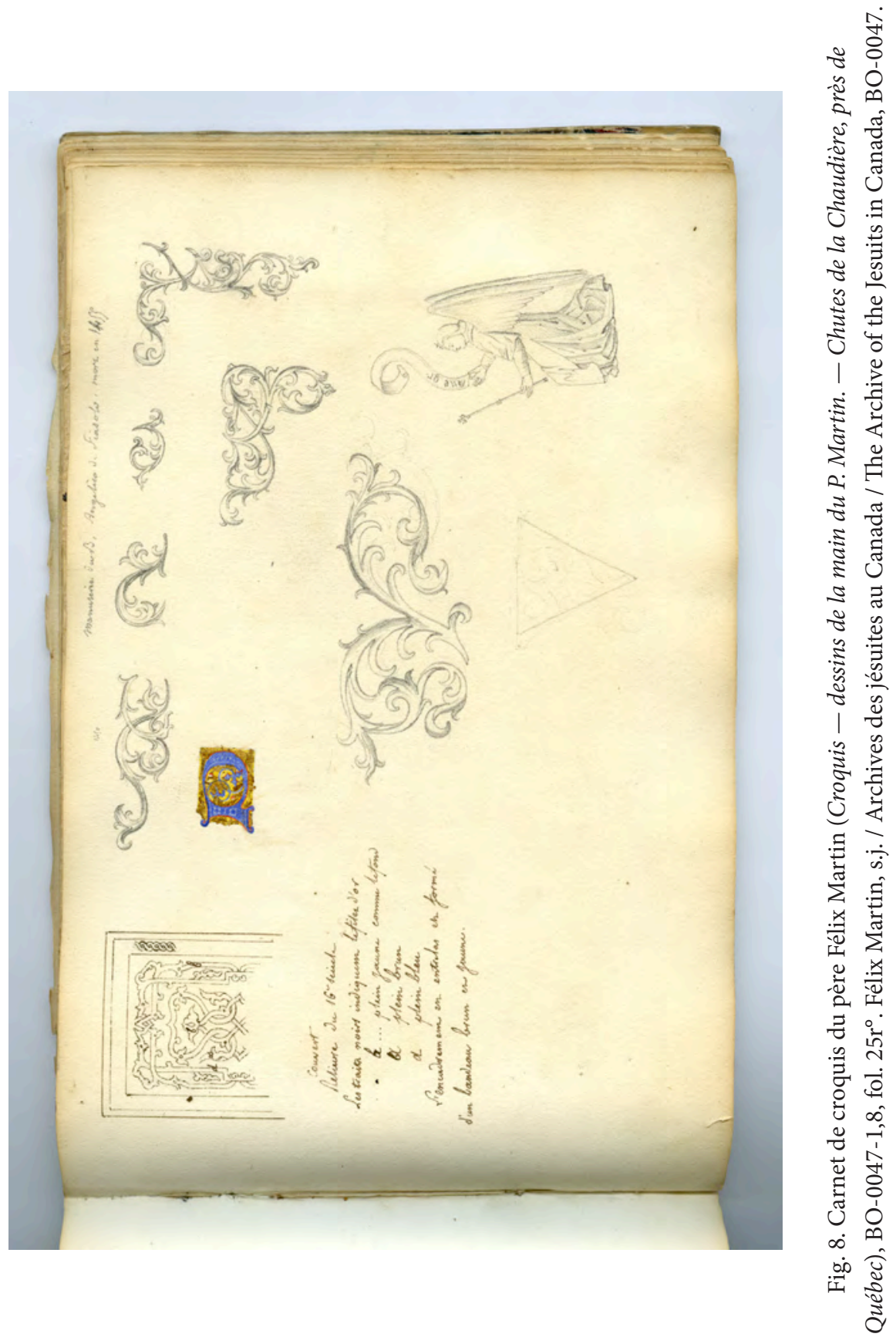
Partant de ces considérations sur la copie d'enluminure, quelques questions émergent. Mis à part la restitution de manuscrits originaux planifiée par les religieuses de l'Hôtel-Dieu de Québec, les dons, legs et achats qui grossirent le fonds général des Archives du Collège Sainte-Marie au XIX ${ }^{\mathrm{e}}$ siècle comprirent-ils un ou deux livres d'Heures par lesquels le père Félix Martin, en fin observateur et grand amateur d'art médiéval, eût pu être charmé ? Plus précisément, l'un des deux livres d'Heures conservés aujourd'hui aux Archives des jésuites au Canada ne devint-il la propriété des jésuites quau $\mathrm{XIX}^{\mathrm{e}}$ siècle, à la faveur d'un don ou d'un legs ? Si tel était le cas, cela voudrait dire que la valeur historique intrinsèque des Heures de Philippe de Montholon et du manuscrit MS- 1 In- $12^{\circ}$ justifia à elle seule l'intégration de ces ouvrages au contenu de l'exposition de 1897 consacrée aux manuscrits des premiers missionnaires jésuites en Amérique du Nord. L'un des deux livres d'Heures rejoignit-il au XIX ${ }^{e}$ siècle les manuscrits des premiers missionnaires dans le cadre d'expositions nationales et internationales, sans qu'un lien l'associât historiquement aux jésuites de la Nouvelle-France ? Cela est possible. Toutes ces questions demeurent pertinentes, en particulier en ce qui a trait au plus petit des deux manuscrits, conservé sous la cote MS- 1 In- $12^{\circ}$ et ayant appartenu à un certain «P Bouthillier» (sur lequel nous nous pencherons brièvement dans la partie 5 de cet article).

Lors d'une conférence qu'il prononça le 29 janvier 1919 sur les Archives du Collège Sainte-Marie, devant les membres de la Société historique de Montréal, l'archiviste jésuite Arthur Melançon ${ }^{48}$ se livra à un exercice de mémoire, en précisant d'entrée de jeu : "À M. [Jacques] Viger, fondateur de la Société Historique de Montréal, premier bienfaiteur de nos archives, devait aller tout naturellement mon premier souvenir, ma première parole de reconnaissance $»^{49}$. À son arrivée au Canada, soulignait le père Melançon, la

48. Le père Arthur Melançon fut l'archiviste du Collège Sainte-Marie de 1918 à 1941, succédant au père Arthur Edward Jones.

49. Arthur Melançon, s.j., « Les Archives du Collège Ste-Marie » (Conférence lue à la Société historique de Montréal, 29 janvier 1919), 2 (AJC. Fonds Arthur Melançon, s.j., BO-0080-4, 5a). Loriginal manuscrit ainsi que le texte dactylographié de la conférence sont conservés sous cette cote aux Archives des jésuites au Canada. L'ancien maire de Montréal, Jacques Viger (1787-1858), fut l'un des fondateurs et le premier président de la Société historique de Montréal, créée en 1858. C’est lui qui aurait suggéré « de fonder à Montréal une société ayant pour but d'étudier l'histoire canadienne, de recueillir et de publier des documents à ce sujet ", proposition ayant mené à la création de la Société historique de Montréal 
bonne fortune voulut que le père Félix Martin rencontrât des hommes «qui pouvaient le renseigner bien et vite : Bibaud ${ }^{50}$, Faribault ${ }^{51}$, et surtout Jacques

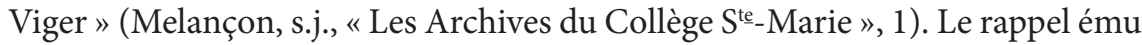
de l'amitié qui lia Félix Martin et l'ancien maire de Montréal, Jacques Viger, culminait dans cette formule : " [e]ntre ces deux esprits si bien faits pour se comprendre ne tarda pas à naître une de ces étroites amitiés qui va jusqu'à l'intimité, à la collaboration, à la communication des biens " (Melançon,

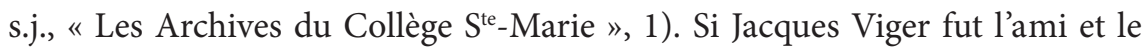
collaborateur du père Martin, il fut aussi un bienfaiteur notoire des Archives du Collège Sainte-Marie, confiant bon nombre de manuscrits, de livres et de brochures aux jésuites (Melançon, s.j., "Les Archives du Collège S ${ }^{\text {te }}$-Marie », 2). Collectionneur, érudit, " compilateur inlassable», Jacques Viger consacra une grande partie de sa vie, soit une quarantaine d'années, à la constitution d'un riche fonds documentaire, que connurent et fréquentèrent les étrangers intéressés par l'histoire du Canada - dont le père Martin était ${ }^{52}$. Il se fit l'ardent promoteur de la recherche et de la conservation de manuscrits anciens, dont il jugeait important de réaliser une ou des copies, à dessein de les publier et

(Nathalie Hamel, "Collectionner les "monuments" du passé : la pratique antiquaire de Jacques Viger ", Revue d'histoire de l'Amérique française 59.1-2 (été-automne 2005) : 77-81).

50. Michel Bibaud (1782-1857), professeur, journaliste, auteur, fonctionnaire et juge de paix. Il publia une Histoire du Canada sous la domination française en 1837 et une Histoire du Canada et des Canadiens sous la domination anglaise en 1844. C’était «la première fois qu'un natif du Canada écrivait l’histoire de son propre pays » (Céline Cyr, «Bibaud, Michel », Dictionnaire biographique du Canada, vol. 8, consulté le 29 mai 2015, http://www.biographi.ca/fr/bio/bibaud_michel_8F.html ; La Fondation Lionel-Groulx, « Histoire du Canada (Michel Bibaud) », Bibliothèque de l'histoire du Québec, consulté le 29 mai 2015, http://www.fondationlionelgroulx.org/Histoire-du-Canada-Michel-Bibaud.html).

51. Georges-Barthélemi Faribault (1789-1866), avocat, fonctionnaire et bibliographe. Il publia un Catalogue d’ouvrages sur l'histoire de l'Amérique, et en particulier sur celle du Canada, de la Louisiane, de l'Acadie, et autres lieux en 1837. En 1852, lors d'un voyage en Europe, il « sétait rendu célèbre auprès des savants et des chercheurs en découvrant à Paris [...] les Relations pour les années 1655 et 1659 ». Entre 1852 et 1855 , il assura la réalisation d'un projet de transcription de documents relatifs à la NouvelleFrance (Yvan Lamonde, "Faribault, Georges-Barthélemi », Dictionnaire biographique du Canada (Université Laval, University of Toronto, 2003-), vol. 9, consulté le 29 mai 2015, http://www.biographi. ca/fr/bio/faribault_georges_barthelemi_9F.html). Voir aussi Georges-Émile Giguère, s.j., " Sous les auspices du gouvernement canadien ", Revue d'histoire de l'Amérique française 8.3 (décembre 1954): 362 .

52. Voir Nathalie Hamel, 76-78. 
de les rendre accessibles aux chercheurs ${ }^{53}$. L'étendue de la "bibliothèque créée par sa plume infatigable » lui valut d’être considéré comme le «Bénédictin du Canada $»^{54}$. Jacques Viger rassembla donc, copia, analysa, commenta des écrits (concernant l'histoire du pays) qui purent servir à d'autres historiens ${ }^{55}$. Quant aux manuscrits et copies de manuscrits qu'il laissa aux jésuites, parmi lesquels se trouve son opuscule critique Le Chien d'or, ou, la tradition en défaut, une liste en est fournie dans un document au titre clair, qui est déposé aux Archives des jésuites au Canada : "Liste des Manuscrits de M. Jacques Viger qui se trouvent dans nos Archives $»^{56}$.

Le père Félix Martin et lui annotèrent ensemble une copie du Journal des jésuites, que les Archives des jésuites au Canada conservent sous le titre de Diarium, ou, Journal des jésuites annoté par M. Jacques Viger et par le P. Felix Martin S.J. ${ }^{57}$. Le manuscrit original du Journal des jésuites (du moins ce qu'il en restait) fut la propriété de Georges-Barthélemi Faribault, qui le légua par testament au Séminaire de Québec ${ }^{58}$. Ce furent les abbés Charles-Honoré Laverdière et Henri-Raymond Casgrain qui publièrent, en 1871, la première édition du Journal des jésuites, ce " complément indispensable des Relations des Jésuites », d’après le manuscrit original conservé au Séminaire de Québec ${ }^{59}$.

53. Voir Nathalie Hamel, 73-94 ; Jean-Claude Robert, « Viger, Jacques », Dictionnaire biographique du Canada, vol. 8, consulté le 27 mai 2015, http://www.biographi.ca/fr/bio/viger_jacques_8F. html.

54. Le répertoire national, ou, recueil de littérature canadienne, compilé et publié par J. Huston (Montréal : De l'imprimerie de Lovell et Gibson, 1848), II : 374-375, n. 1 ; Desjardins, 32.

55. Voir Giguère, «Sous les auspices du gouvernement canadien », 359-379 ; Nathalie Hamel, 73-94 ; Robert, «Viger, Jacques », Dictionnaire biographique du Canada.

56. Cette liste est reliée avec d’autres documents, sous le titre Histoire des archives du Collège SainteMarie (voir AJC. Fonds Arthur Melançon, s.j., BO-0080, 5a).

57. 1645-1668 : Diarium, ou, Journal des jésuites annoté par M. Jacques Viger et par le P. Felix Martin S.J. Papiers du P. Fx. Martin (AJC. Fonds Archives, Collège Sainte-Marie, Q-0001, CACSM 1, dossier 2219). Voir Desjardins, 33-34.

58. Georges-Barthélemi Faribault était de ceux qui, avec Félix Martin et Jacques Viger, s’intéressaient de près aux Relations des jésuites du XVII ${ }^{e}$ siècle et au projet de leur réédition au XIX siècle. Voir Giguère, "Sous les auspices du gouvernement canadien ", 369-373.

59. MM. les abbés Laverdière et Casgrain, éd., Le Journal des jésuites, publié d’après le manuscrit original conservé aux archives du Séminaire de Québec, (Québec : Léger Brousseau, 1871), vii, v. Les éditeurs faisaient observer dans leur préface que le Journal des jésuites « embrassait plus d'un siècle de notre histoire, de 1645 à 1755, sans presque aucune interruption », mais que, hélas, « là-dessus [...] il ne nous rest[ait] pas vingt-deux années complètes !» (ix-x). 
Contrairement aux Relations, le Journal des jésuites n'était pas destiné à un lectorat européen. Les auteurs successifs y consignèrent plutôt, jour par jour, " une foule de détails intimes ${ }^{60}$ utiles aux membres de la Compagnie de Jésus. En somme, comme le rappelaient les abbés Laverdière et Casgrain dans leur préface, «[c]e précieux manuscrit paraît être le premier journal régulier qu'aient tenu les Jésuites en Canada $»^{61}$. À titre d'exemple, un relevé minutieux des échanges de lettres et autres biens ayant eu cours en janvier 1648 entre les différents acteurs de la communauté (jésuites, laïcs, religieuses hospitalières et ursulines) rendait méthodiquement compte de la circulation et de la transmission de certains objets (livres, livrets, livres d'Heures, etc.) dans la colonie :

Les Hospitalieres envoyerent le matin une lettre par M. de St. Sauveur, \& le soir d'auparavant un petit quart de vin d'Espagne d'environ 4. pots; je leur envoyé une lettre le mesme jour, \& un livre, l'abrégé du P. Suffren ${ }^{62}$.

Je donné à M. de St. Sauveur une bougie \& un Gerson ${ }^{63}$; il demanda une calote, que je luy fis faire.

60. Le Journal des jésuites, publié d’après le manuscrit original, $\mathrm{v}$.

61. Le Journal des jésuites, publié d’après le manuscrit original, vii.

62. Le jésuite Jean Suffren (1565-1641) fut le confesseur de Marie de Médicis et de Louis XIII. Il est l'auteur, entre autres, de L'année chrestienne, ou, le sainct et profitable employ du temps pour gaigner l'Eternité, où sont enseignées diverses pratiques et moyens pour saintement s'occuper durant tout le cours de l'année, conformément à l'ordre de l'année, inspiré par le Sainct Esprit à l'Eglise Chrestienne (Paris : Claude Sonnius, 1641) et de Pratiques et exercices de devotion pour bien employer les festes solennelles et autres saincts jours de lannée (Paris : Claude Sonnius et Denys Bechet, 1645). Voir Augustin et Alois de Backer, Bibliothèque des écrivains de la Compagnie de Jésus, deuxième série, (Liège : Imprimerie de L. Grandmont-Donders, 1854), 603-604.

63. Jean Charlier, dit Jean Gerson (1363-1429), théologien et auteur spirituel. Jean Gerson succéda à Pierre d'Ailly au poste de chancelier de l'Université de Paris, le 13 avril 1395. « Le succès prodigieux de l'Imitation de Jésus-Christ, dont on [le crut] longtemps l'auteur et avec laquelle on imprimait des œuvres authentiquement gersoniennes, [contribua] pour une bonne part à la faveur rencontrée par les écrits spirituels du chancelier ». Au XVII siècle, l'influence de Jean Gerson se fit sentir particulièrement chez François de Sales, qui avait une haute estime pour la personne et l’œuvre du chancelier. Une édition des Opera omnia de Gerson fut publiée à Paris en 1606 par Edmond Richer. En 1645, Nicolas Guillebert proposa une traduction française de la Josephina (Paris, P. Rocolet), qui témoignait de la dévotion toute spéciale que Gerson portait à saint Joseph (Palémon Glorieux, «Gerson (Jean) », Dictionnaire 
Les Ursulines envoyerent une lettre, \& une croix de relique pour moy, un pain de bougie au P. Lyonne \& au P. le Jeune, \& à disner le jour de la Circoncision. Je leur envoyé une lettre, \& une image dans un quadre pour l'oratoire de leur classe.

Je donné à Pierre, celuy qui tenoit le lutrain, un estuy, une image, chapelet \& livret. A Mons. \& Madame Bourdon, un reliquaire, des heures \& un abregé du P. Suffren. A nos PP. \& FF., \&c., le soir, une grande image enluminée de velin, \& j’en envoyé autant à Sillery ${ }^{64}$.

En parlant des manuscrits de la Nouvelle-France conservés aux Archives du Collège Sainte-Marie, l'archiviste Arthur Edward Jones exposait cette nuance au père Camille de Rochemonteix, à la fin du XIX ${ }^{\mathrm{e}}$ siècle : « [...] nous avons, il est vraie (sic), plusieurs documents originaux bien précieux mais ce ne sont plus que de[s] reliques, car le P. Felix Martin, et Mons. J. Gilmary Shea (de New York) les ont publiés depuis longtemps $»^{65}$.

\subsection{Le trésor inestimable mis en valeur par le père Arthur Edward Jones à la fin du XIX ${ }^{\mathrm{e}}$ et au début du $\mathrm{XX}^{\mathrm{e}}$ siècle}

Ces manuscrits devenus reliques composèrent, dans une certaine mesure, le trésor inestimable que les jésuites consentirent à prêter lors d'expositions qui se tinrent à Montréal, New York, Toronto, Saint-Louis (Missouri) et Chicago, entre 1892 et 1904. En un peu plus de douze ans, les manuscrits des Archives du Collège Sainte-Marie furent mis à l'honneur dans le cadre d'au moins six expositions, organisées successivement par la Société de Numismatique et d'Archéologie de Montréal (1892), la Montreal Free Library (1894), le Catholic Club de New York (1897), le Victoria College de Toronto (1899), la Louisiana Purchase Exposition de Saint-Louis, au Missouri (1904), et la Chicago Historical Society $(1904)^{66}$. Le mérite en revint au père Arthur Edward Jones,

de spiritualité ascétique et mystique : doctrine et histoire [Paris : Beauchesne, 1967], VI : cols. 314, 330, 326).

64. Le Journal des jésuites, publié d’après le manuscrit original, 99.

65. AJC. Fonds Arthur Edward Jones, s.j., BO-0035-9, 4 ; AJC. Fonds Édouard Désy, s.j., BO-0078-13, 85. Voir plus haut, n. 1,10 et 37.

66. Voir France Lord, La muette éloquence des choses : collections et expositions missionnaires de la Compagnie de Jésus au Québec, de 1843 à 1946, 2 vols. (Université de Montréal, Thèse de doctorat, 
qui dirigeait les Archives depuis 1882 et qui était considéré alors comme le plus grand spécialiste des expéditions missionnaires jésuites en Nouvelle-France, soit la plus grande figure d'autorité dans ce domaine ${ }^{67}$. En retraçant l'histoire de ces Archives devant les membres de la Société historique de Montréal en janvier 1919, le père Arthur Melançon, qui fut l'adjoint du père Jones pendant six ans avant de lui succéder, en 1918, se remémorait les gestes précautionneux de son prédécesseur à l'endroit des manuscrits anciens :

Ces manuscrits, il les dorlote, il les manie avec délicatesse, il les répare en artiste, leur conservant l'apparence primitive, il les enferme dans des étuis bien travaillés ; bref, il en prend un soin infini. Ils deviennent comme sa propriété ; il les prête à contre cœur, il s'inquiète dès qu'il les sait entre d'autres mains $[\ldots]^{68}$.

Sur quoi nous pouvons apprécier sous un nouveau jour le commentaire autographe du père Jones : "All brought back safely. A. E. Jones, S.J. », inscrit sur la couverture du catalogue Exhibit of Manuscripts of the Early Jesuit Missionaries in North America from St. Mary's College, publié à New York en 1897 (voir plus haut fig. 6). Des crochets tracés au crayon bleu devant chacune des entrées du catalogue (voir plus haut fig. 7) suggèrent qu'une liste de contrôle prise à même ce document permit au père Jones de vérifier que toutes les pièces prêtées furent effectivement retournées à leurs propriétaires.

Dans les catalogues des expositions new-yorkaise et torontoise de 1897 et 1899 (voir fig. 7 et 15), les Heures de Philippe de Montholon et le manuscrit MS-1 In- $12^{\circ}$ furent implicitement assimilés aux manuscrits des premiers missionnaires jésuites en Amérique du Nord ( Manuscripts of the Early Jesuit Missionaries in North America »). Comme leurs origines et leur contenu n'entretenaient aucun lien spécifique avec l'histoire de la Compagnie de Jésus

1999), $1: 75-76$.

67. « Father Jones is archivist of St. Mary's College, Montreal and doubtless the highest living authority on the movements of the Jesuit missionaries of New France ». Rev. Arthur Edward Jones, « The Site of the Mascoutin ", in The Mascoutin of Fox River Valley (Madison : State Historical Society of Wisconsin, 1907), 175, n. 1, de l'éditeur (AJC. Fonds Archives, Collège Sainte-Marie, Q-0001, CACSM 1, dossier 1490, 29). Voir également « Jones, Arthur E. ", Dictionary of Jesuit Biography : Ministry to English Canada, 1842-1987 (Toronto : Canadian Institute of Jesuit Studies, 1991), 157-158.

68. Melançon, «Les Archives du Collège Ste-Marie », 8. Voir plus haut, n. 49. 
au Canada, il semble aller de soi que les deux manuscrits enluminés ne purent être présentés dans ces expositions qu'à titre de pièces exceptionnelles. Ou de reliques. À plus forte raison si l'un ou l'autre des deux ouvrages était passé entre les mains d'un Charles Garnier, d'une Marie de l'Incarnation, ou d'une Marie de Saint-Bonaventure-de-Jésus, par exemple.

3.2.1. Le $250^{\mathrm{e}}$ anniversaire de la fondation de Ville-Marie et l'exposition de 1892

Pour commémorer le $250^{\mathrm{e}}$ anniversaire de la fondation de Ville-Marie, la Société de Numismatique et d'Archéologie de Montréal organisa une exposition historique particulière, qui eut lieu conjointement avec l'Exposition provinciale, au mois de septembre 1892. Le mois précédent, une lettre circulaire avait été acheminée aux Archives du Collège Sainte-Marie, dans laquelle le secrétaire honoraire du Comité de l'Exposition, Archibald Chaussegros de Léry Macdonald, esquissait le projet à grands traits, ajoutant que la Société comptait, grâce à cet événement, " réveiller l'intérêt du public sur la richesse de notre pays en portraits et souvenirs historiques et montrer qu'il exist[ait] de quoi former un musée et une galerie nationale où figureraient ceux qui ont illustré notre pays ${ }^{69}$ :

La Société sollicite votre concours pour mener à bonne fin cette entreprise patriotique, en envoyant les portraits ou reliques qui sont en votre possession ou en prévenant le Comité de l'existence d'objets d'intérêt archéologique.

Les objets qui devront être exposés seront classifiés comme suit :-

$1^{\circ}$ Reliques des Sauvages.

$2^{\circ}$ Vues et Plans Anciens.

$3^{\circ}$ Documents, Autographes et Sceaux.

$4^{\circ}$ Livres se rapportant au Canada et anciens imprimés Canadiens.

$5^{\circ}$ Médailles et monnaies Canadiennes.

$6^{\circ}$ Argenteries et porcelaines anciennes.

$7^{\circ}$ Drapeaux, enseignes et fanions.

$8^{\circ}$ Armes et buffleterie.

69. Lettre circulaire datée du 9 août 1892, signée par « A. C. de Léry Macdonald, Sec. Hon. » (AJC. Fonds Archives, Collège Sainte-Marie, Q-0001, CACSM 1, 1474). 
$9^{\circ}$ Uniformes Militaires et Costumes de l'ancien régime.

$10^{\circ}$ Anciens Meubles, Bric-à-brac, etc.

$11^{\circ}$ Portraits (miniatures, gravures, pastels, toiles, crayons, etc.,) de toute personne ayant joué un rôle quelconque dans notre histoire, soit dans l'état ecclésiastique, militaire ou politique, soit dans la magistrature ou dans le commerce, pourvu que cette personne ait figuré avant 1840.

Un Catalogue raisonné, donnant le détail de chaque exhibit et le nom du prêteur sera publié $[\ldots]^{70}$.

Dans le catalogue publié en 1892 - A Record of Canadian Historical Portraits and Antiquities Exhibited by the Numismatic and Antiquarian Society of Montreal, 15 $5^{\text {th }}$ September 1892, in Commemoration of the 250 ${ }^{\text {th }}$ Year of the Foundation of Montreal (fig. 9) - une section fut consacrée au trésor des Archives du Collège Sainte-Marie, dont le père Arthur Edward Jones avait assuré la reconstitution. Étant donné leur ancienneté, les Heures de Philippe de Montholon et le manuscrit MS-1 In-12 (désignés comme " psautiers ») figuraient en tête de liste, sous la rubrique "Manuscripts, Books ; Etc. », qui regroupait également des manuscrits, imprimés et fac-similés des XVII ${ }^{e}, \mathrm{XVIII}^{\mathrm{e}}$ et XIX ${ }^{\mathrm{e}}$ siècles (fig. 10 et 11 ) :

16 - 1522 Psalter belonging to the de Montholon family.

17 - Small Psalter of the 16 Century $^{71}$.

\subsubsection{La Montreal Free Library et l'exposition de 1894}

Il en fut de même dans le catalogue d'une exposition organisée moins de deux ans plus tard, en avril 1894, à l'initiative du père Jones, pour soutenir financièrement la Montreal Free Library. Euvre jésuite logée dans les locaux du Gesù, attenant au collège Sainte-Marie, la Montreal Free Library, qui avait

70. Lettre circulaire datée du 9 août 1892, signée par « A. C. de Léry Macdonald, Sec. Hon. » (AJC. Fonds Archives, Collège Sainte-Marie, Q-0001, CACSM 1, 1474). Ce « [c] atalogue raisonné », avec les détails que nous aurions attendus, ne semble pas avoir existé, le seul catalogue disponible ne présentant que des titres abrégés.

71. A. C. de Léry Macdonald, éd., A Record of Canadian Historical Portraits and Antiquities Exhibited by the Numismatic and Antiquarian Society of Montreal, $15^{\text {th }}$ September 1892, in Commemoration of the $250^{\text {th }}$ Year of the Foundation of Montreal [1892], 49. 


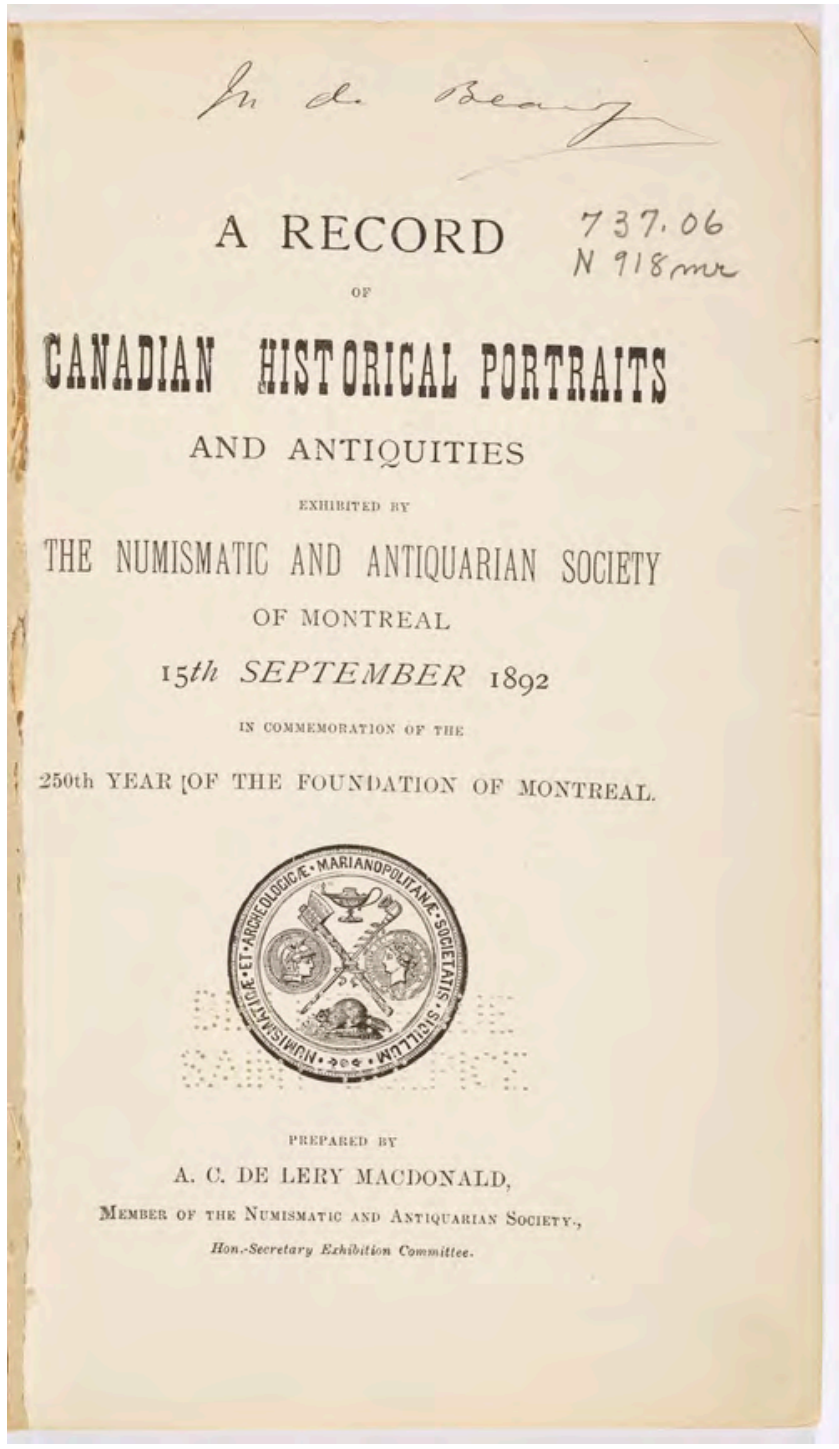

Fig. 9. Page couverture. A. C. de Léry Macdonald, éd., A Record of Canadian Historical Portraits and Antiquities Exhibited by the Numismatic and Antiquarian Society of Montreal, $15^{\text {th }}$ September 1892, in Commemoration of the $250^{\text {th }}$ Year of the Foundation of Montreal [1892]. Cliché Bibliothèque et Archives nationales du Québec. Collection nationale. 757.0971074M1351r 1892. 
ouvert ses portes en octobre 1889, était une «bibliothèque de prêt gratuite à l'usage de la communauté anglo-catholique de Montréal $»^{72}$. Dans le catalogue de l'exposition, publié sous le titre Exhibition of Old Mss., \&C. Selected from the Archives of St. Mary's College for the Free Library Fund, les deux premières entrées étaient également réservées aux manuscrits les plus anciens (voir fig. 12 et 13) :

1- 1522 Psalter belonging to the Montholon family.

2- Small Psalter of the 16 Century $^{73}$.

\subsubsection{L'exposition new-yorkaise de 1897}

En décembre 1897, nous l'avons vu, l'Exhibit of Manuscripts of the Early Jesuit Missionaries in North America, soulignant la réouverture de la bibliothèque du Catholic Club de New York ${ }^{74}$, mettait en valeur les deux « psautiers » des expositions montréalaises de 1892 et 1894, à la différence que le plus petit des deux livres d'Heures ( Small illuminated Psalter of the $14^{\text {th }}$ Century »), qui avait été daté jusque-là du $\mathrm{XVI}^{\mathrm{e}}$ siècle, y était présenté comme un manuscrit enluminé du XIV ${ }^{e}$ siècle (voir plus haut fig. 7 ) $^{75}$. Cette nouvelle datation, attribuée sans plus d'explication, allait se perpétuer, par exemple, dans les catalogues de la Canadian Historical Exhibition présentée à Toronto en 1899 et du Special Loan Exhibit organisé à Chicago par la Chicago Historical Society en 1904 (voir fig. 15 et 20).

72. Yvan Lamonde, «Un aspect inconnu du débat autour de la bibliothèque publique à Montréal : la Montreal Free Library (1889- )», Les Cahiers des dix 57 (2003) : 266, 270.

73. Exhibition of Old Mss., \&C. Selected from the Archives of St. Mary's College for the Free Library Fund. 1894. April 10, 11, $12^{\text {th }} .8$ to 10 P.M. (Montreal : W. Boucher Imprimeur, [1894]), 3 (AJC. Fonds Arthur Melançon, s.j., BO-0080-13, 8 ; AJC. 1894, 14).

74. Voir John Jerome Rooney, "The Catholic Club of New York », The Catholic Encyclopedia (New York : Robert Appleton Company, 1908), vol. 6, consulté le 8 juin 2015, http://www.newadvent.org/ cathen/03452b.htm.

75. De fait, le manuscrit est probablement un ouvrage de la fin du XVe siècle. Voir plus haut n. 3. 

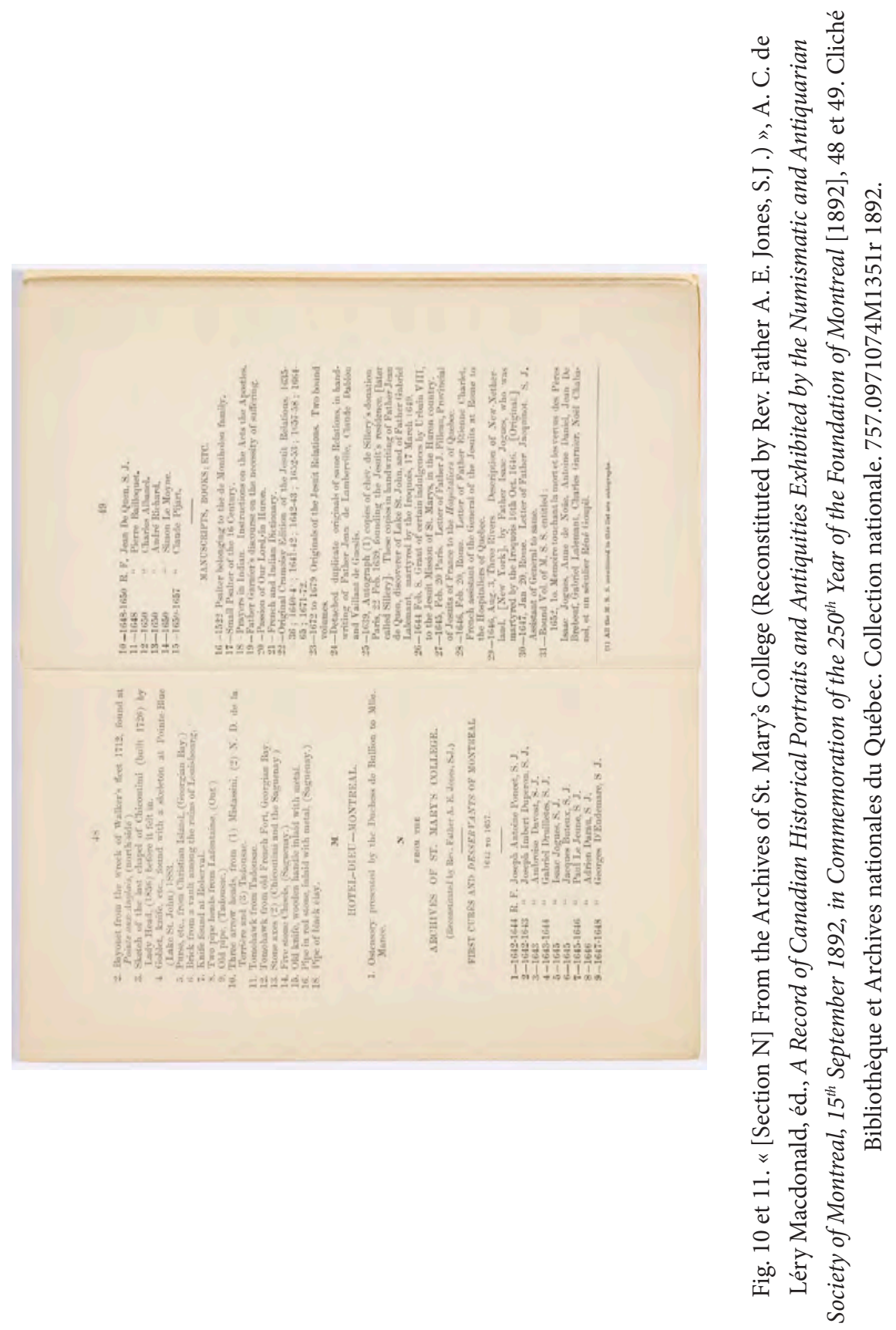


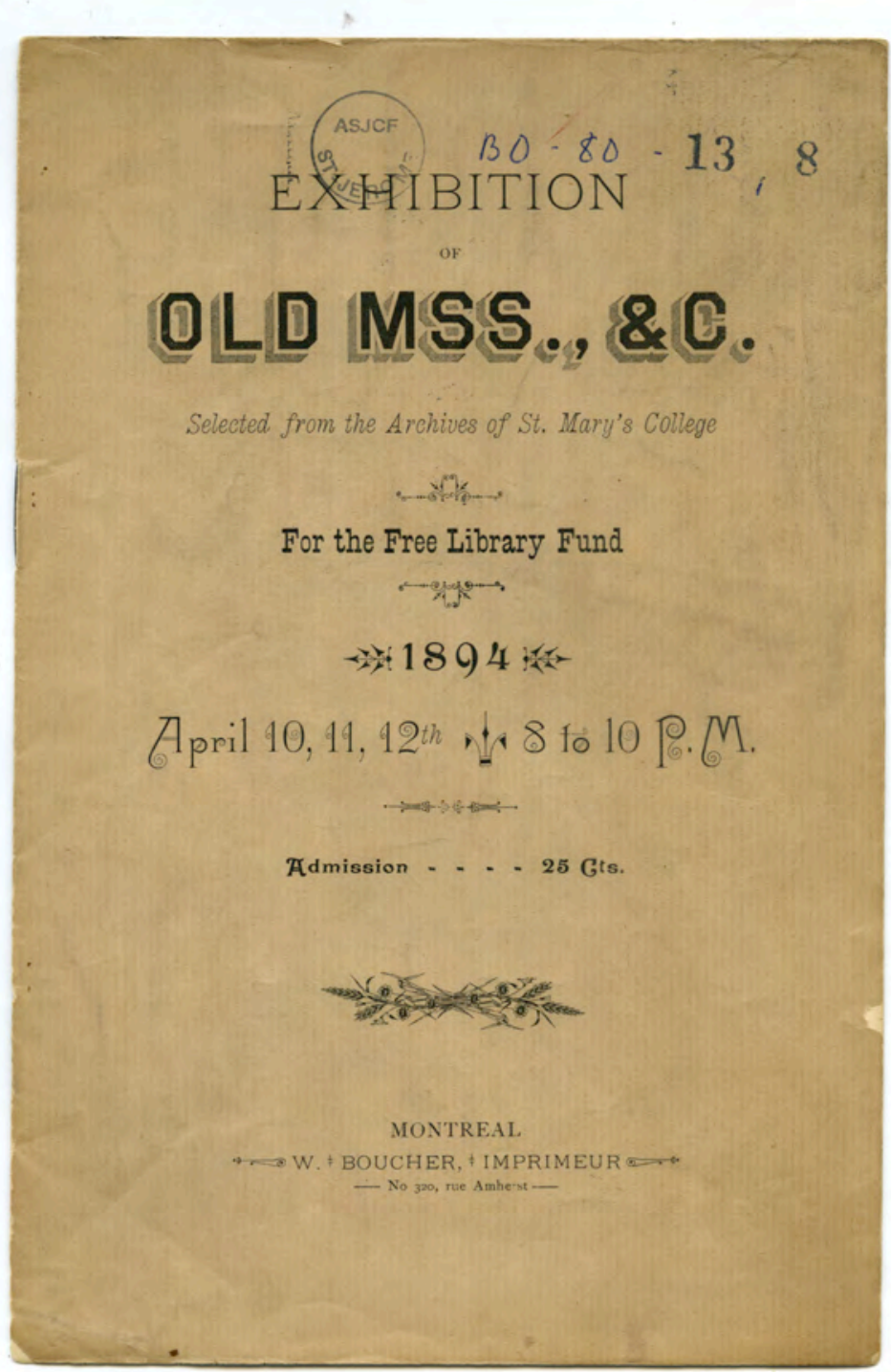

Fig. 12. Page couverture. Exhibition of Old Mss., \&C. Selected from the Archives of St. Mary's College for the Free Library Fund. 1894. April 10, 11, $12^{\text {th }} .8$ to 10 P.M. (Montreal : W. Boucher Imprimeur, [1894]). Archives des jésuites au Canada / The Archive of the Jesuits in Canada, BO-0080. 
>

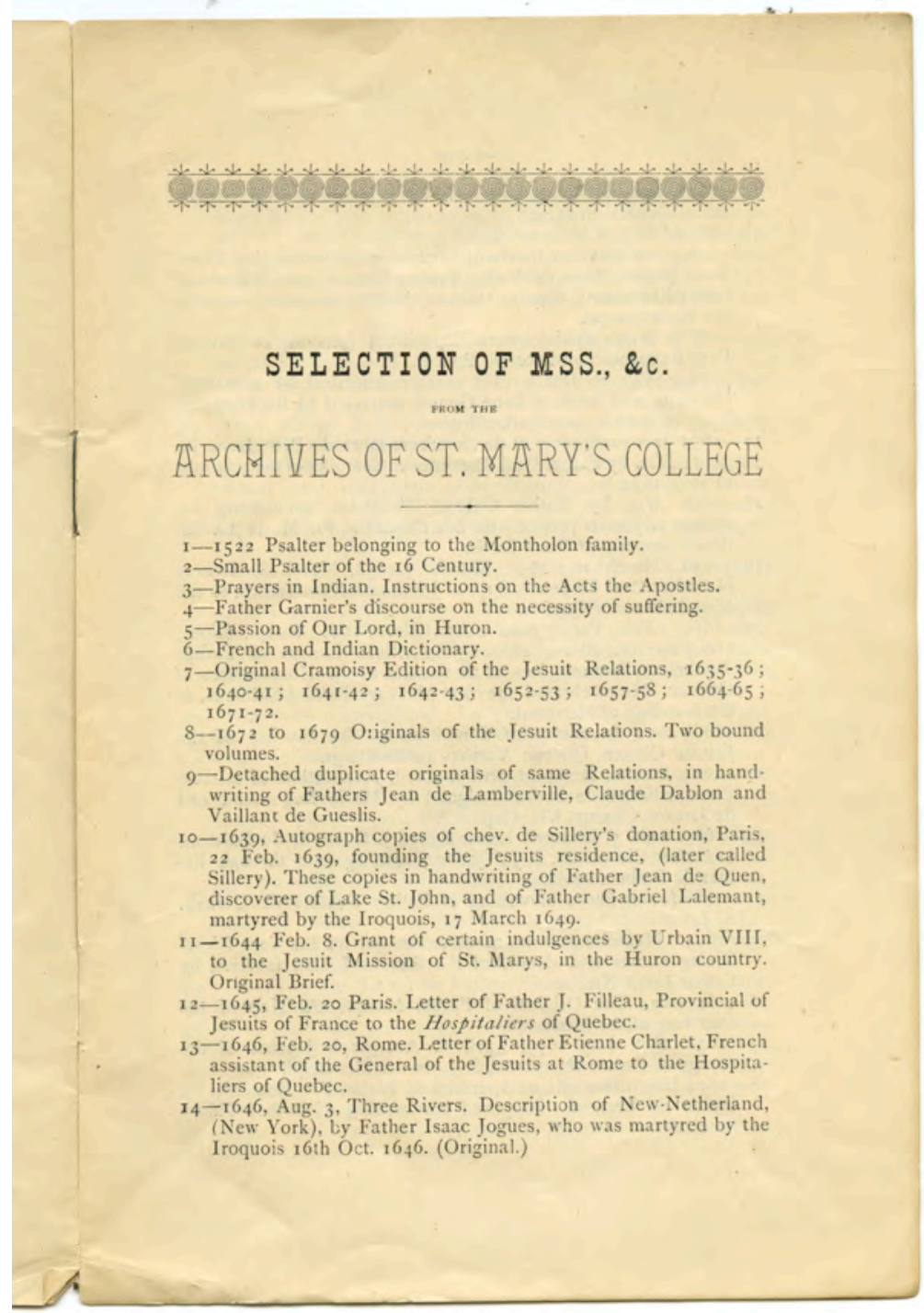

Fig. 13. Exhibition of Old Mss., \&C. Selected from the Archives of St. Mary's College for the Free Library Fund. 1894. April 10, 11, $12^{\text {th }} .8$ to 10 P.M. (Montreal : W. Boucher Imprimeur, [1894]), 3. Archives des jésuites au Canada / The Archive of the Jesuits in Canada, BO-0080. 


\subsubsection{L'exposition torontoise de 1899}

L'exposition présentée au Catholic Club de New York en 1897 fut pour ainsi dire reconduite en partie, lors du déploiement, à Toronto, du trésor du Collège Sainte-Marie, dans le cadre de la Canadian Historical Exhibition, qui se déroula du 14 au 28 juin 1899, sous les auspices de l'Ontario Historical Society (fig. 14 et 15). Il n'y a, pour nous en convaincre, qu'à nous reporter au titre évocateur de la section consacrée aux manuscrits des jésuites : «Exhibit of Manuscripts of the Early Jesuit Missionaries in North America » (voir fig. 15).

Quelques mois auparavant, en mars 1899, le président de l'Ontario Historical Society, James Henry Coyne, avait fait parvenir une lettre engageante au père Arthur Edward Jones ; il y évoquait la possibilité, pour l'archiviste, de présenter son importante collection dans le cadre de la Canadian Historical Exhibition, prévue en juin : si la collection historique du Collège Sainte-Marie était présentée à Toronto, elle serait, de toutes les collections exposées, l'une des plus intéressantes («it will be one of the most interesting of all the exhibits $»^{76}$ ).

3.2.5. 1904 : The Louisiana Purchase Exposition (Saint-Louis, Missouri) et le Special Loan Exhibit de Chicago

C'est en usant de formules superlatives semblables à celle-là que le jésuite William Banks Rogers, président de la St. Louis University (Saint-Louis, Missouri), s'adressa au père Jones, en novembre 1904, pour le convaincre, au nom des membres de la Chicago Historical Society, de prêter à la société en question les joyaux des Archives du Collège Sainte-Marie qui étaient exposés depuis le 30 avril à la Louisiana Purchase Exposition, en vue d'une exposition qui aurait lieu en décembre, pendant le congrès annuel de l'American Historical

76. Lettre adressée au père Arthur Edward Jones, le 27 mars 1899, par James Henry Coyne, président de l'Ontario Historical Society (AJC. Fonds Archives, Collège Sainte-Marie, Q-0001 CACSM 1, dossier 1484.21). Une lettre circulaire concernant la Canadian Historical Exhibition de 1899 de même qu'une lettre personnelle adressée au père Arthur Edward Jones par Mary Agnes FitzGibbon, secrétaire du comité de l'Exposition, sont également conservées aux Archives des jésuites au Canada (voir AJC. Fonds Archives, Collège Sainte-Marie, Q-0001 CACSM 1, dossiers 1484.6 et 1484.7). 


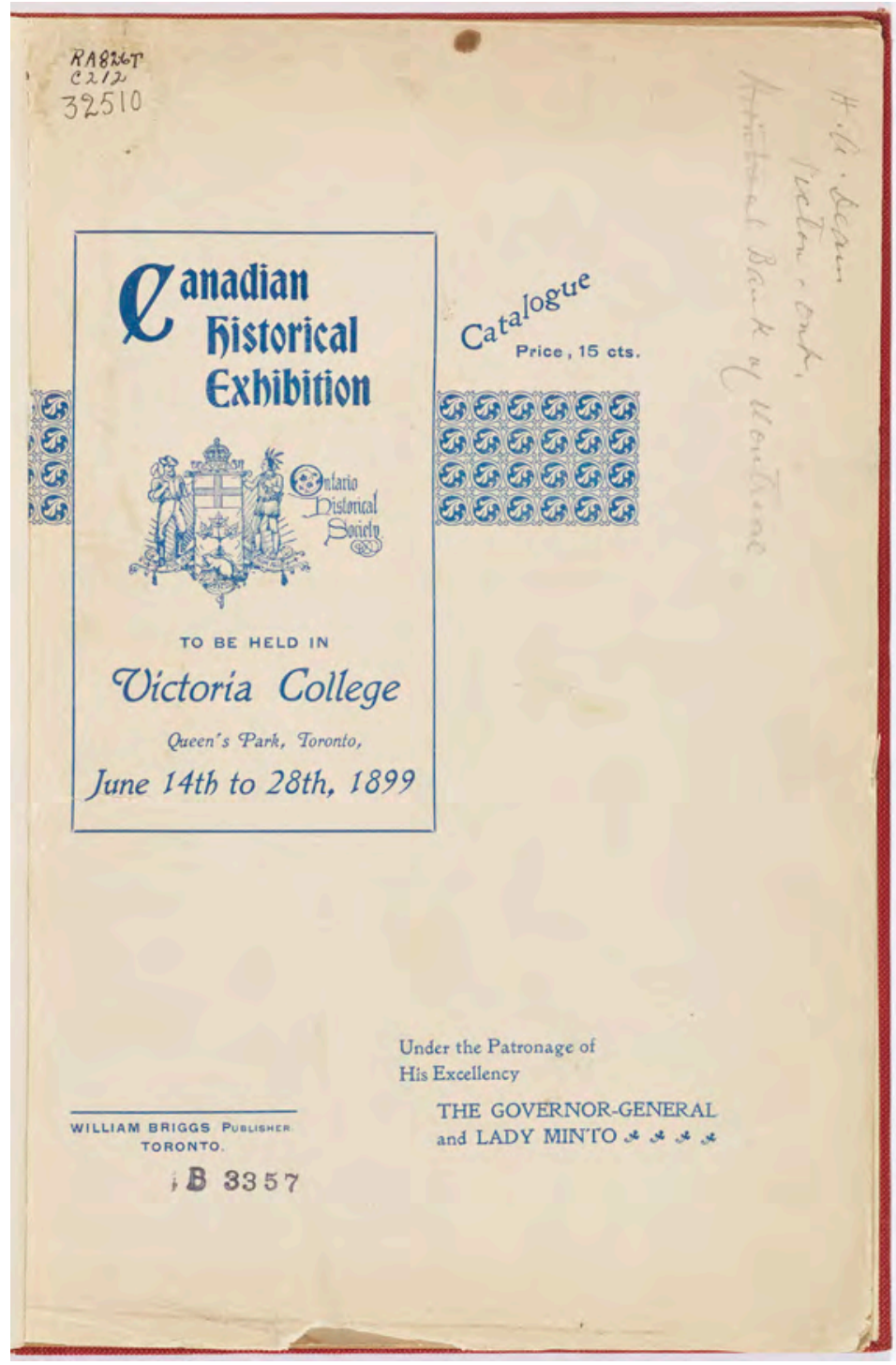

Fig. 14. Page de titre. Catalogue : Canadian Historical Exhibition, Victoria College, Queen's Park, Toronto, under the Patronage of His Excellency the Governor-General and the Countess of Minto, June $14^{\text {th }}$ to $28^{\text {th }}, 1899$ (Toronto : William Briggs, 1899). Cliché Bibliothèque et Archives nationales du Québec. Collection nationale. C 971.0063 O59ca 1899. 


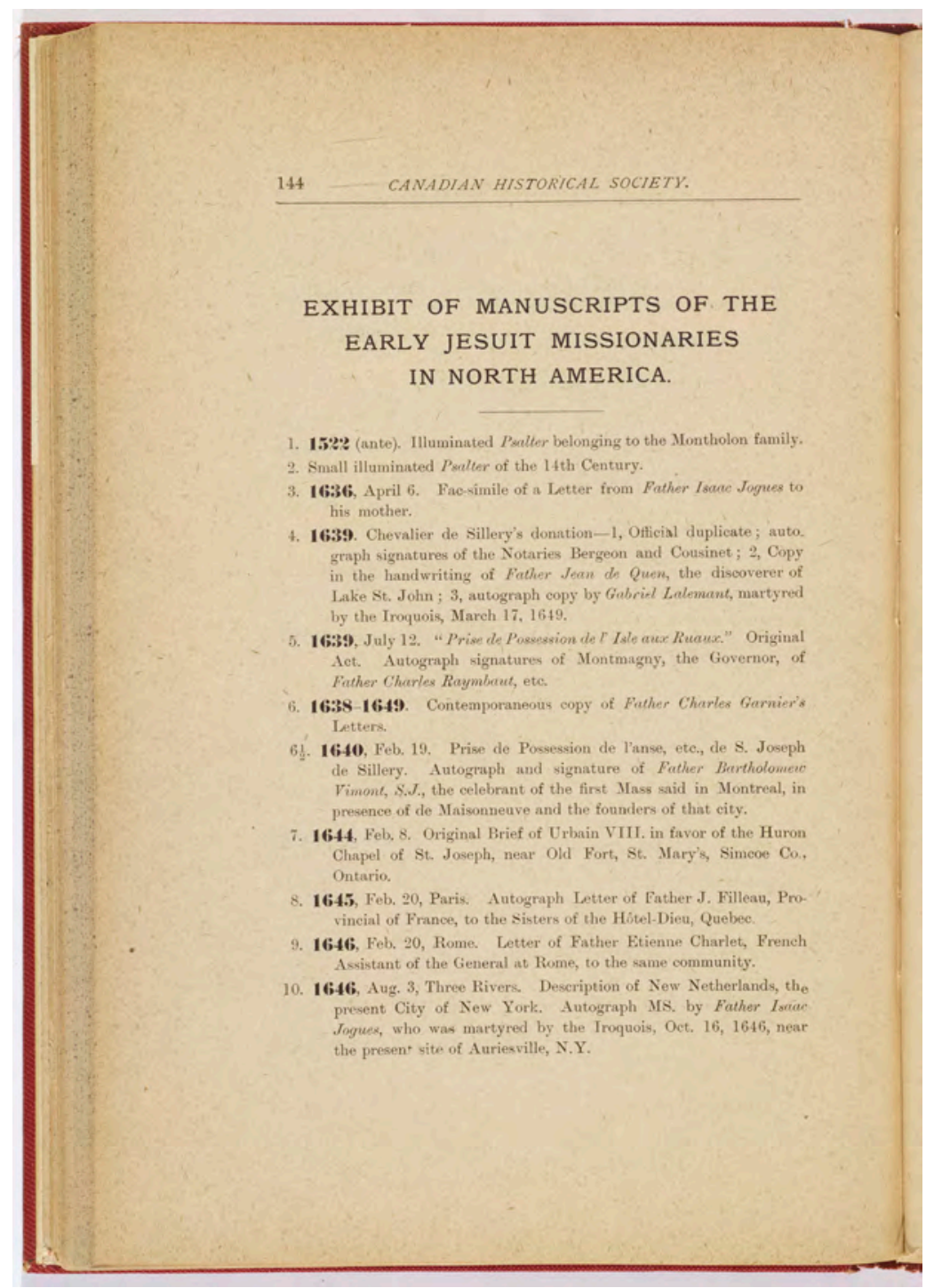

Fig. 15. Catalogue: Canadian Historical Exhibition, Victoria College, Queen's Park, Toronto, under the Patronage of His Excellency the Governor-General and the Countess of Minto, June $14^{\text {th }}$ to $28^{\text {th }}, 1899$ (Toronto : William Briggs, 1899) 144. Cliché Bibliothèque et Archives nationales du Québec. Collection nationale. C 971.0063 O59ca 1899. 
Association ${ }^{77}$. Les congressistes étaient attendus à Chicago à la fin du mois de décembre, quelques semaines après la soirée de clôture de la Louisiana Purchase Exposition, qui devait prendre fin le $1^{\text {er }}$ décembre 1904, à Saint-Louis, dans l'État du Missouri. Les organisateurs de la Louisiana Purchase Exposition avaient voulu que celle-ci coïncidât, en 1904, avec l'Exposition universelle de Saint-Louis (St. Louis World's Fair), pour marquer le centenaire de la vente de la Louisiane aux États-Unis par la France (survenue en 1803). Dans sa lettre du 15 novembre 1904, le père William Banks Rogers salua l'inégalable qualité des documents présentés par le père Jones à l'Exposition universelle de Saint-Louis et il s'appliqua à infléchir favorablement la décision de ce dernier, en prévenant les objections qu’il eût pu opposer au projet d'exposition de la Chicago Historical Society :

I enclose herewith a letter sent [to] me from the Chicago Historical Society a few days ago, asking to have the best, and what I consider, the most valuable documents at the Fair ${ }^{78}$, for a meeting of the Historical Society, which is to take place in Chicago [...]. These people are very careful, and I will be very glad if you can accomodate them by letting them have a part of your treasures. At the same time, you yourself will have to decide what must be done [...] In case the documents should go to Chicago would you be able to go there and meet the distinguished historians who will be present ? If you should do this, I think it would be well. Should you be willing to allow your treasures to go to Chicago, but be unable to be present yourself, I shall try to arrange to have some one go up from here, or have some of our Fathers in Chicago take charge of the ex[h]ibit and see that it is safely packed and reaches you in good order ${ }^{79}$.

Le père Arthur Edward Jones consentit, avec l'approbation de ses supérieurs, à faire voyager les documents précieux jusqu’à Chicago, au terme

77. Les copies de quelques lettres concernant cet événement sont conservées dans le fonds des Archives du Collège Sainte-Marie (AJC. Fonds Archives, Collège Sainte-Marie, Q-0001 CACSM 1, dossiers 1489, 9 à 1489,12$)$.

78. L'Exposition universelle de Saint-Louis (St. Louis World's Fair ou The Louisiana Purchase Exposition, 1904). C'est l'auteur qui souligne.

79. Lettre dactylographiée du père William Banks Rogers, envoyée au père Arthur Edward Jones, depuis Saint-Louis (St. Louis University), le 15 novembre 1904, 1-2 (AJC. Fonds Archives, Collège SainteMarie, Q-0001 CACSM 1, dossier 1489, 12). 
de la Louisiana Purchase Exposition, qui prenait fin le $1^{\text {er }}$ décembre. Les Archives des jésuites au Canada conservent plusieurs lettres, articles, cartons de participation, etc., qui nous informent sur les déplacements et les engagements du père Jones à cette époque, notamment à la Louisiana Purchase Exposition de Saint-Louis (voir fig. 16 et 17), où il fut honoré, puis au Special Loan Exhibit de Chicago, qui eut lieu pendant le congrès annuel de l'American Historical Society. Par exemple, au père Édouard Désy qui s'enquérait de la date de retour du père Jones à Québec, le père Édouard Lecompte, qui était alors Provincial de la mission canadienne, répondit, le 21 novembre 1904 : «Les 20, 21, 22 décembre, il y aura un congrès de l'“American Historical Society" à Chicago. On a supplié le Collège $S^{\text {te }}$ Marie de vouloir bien y exposer son "invaluable" trésor de $\mathrm{S}^{t}$-Louis. Le P. Jones prendra part au Congrès avec le dit trésor ${ }^{80}$.

Lors de la conférence qu'il prononça en 1919 devant la Société historique de Montréal sur l'histoire des Archives du Collège Sainte-Marie, le père Arthur Melançon rappela les honneurs que se méritèrent le père Jones et l'institution qu'il représentait lors de l'Exposition universelle de Saint-Louis :

Lorsque l'Exposition de Saint-Louis fut décidée, le P. Jones ne se donna aucun repos qu'il n'eût obtenu de ses Supérieurs la permission d'y transporter tous ses trésors, et cela toujours dans le même but : faire parler des missionnaires, en faire pénétrer la connaissance parmi le peuple américain. Il était sûr du succès ; il pouvait offrir aux regards émerveillés de la foule le journal autographe du P. Marquette, et on sait la place qu'occupe le P. Marquette dans les pays de l'Ouest. Personne n'ignore le résultat: Grand Prix pour le collège Sainte-Marie, Médaille d'or pour l'archiviste. Le retour fut comme une marche triomphale. Il fallut s'arrêter à Chicago, exposer durant plusieurs jours les manuscrits désormais glorieux, faire des conférences, \&c. De même à Toronto ${ }^{81}$.

80. Lettre manuscrite du père Édouard Lecompte au père Édouard Désy, datée du 21 novembre 1904. L’en-tête de la lettre est celui du Collège Sainte-Marie, Montréal (AJC. Fonds Édouard Désy, s.j., BO0078-14, 71). L'exposition (Special Loan Exhibit by the Chicago Historical Society) fut présentée du 23 au 30 décembre 1904, dans le cadre du congrès annuel de l'American Historical Association, qui se tint du 28 au 30 décembre 1904.

81. Melançon, "Les Archives du Collège Ste-Marie », 10. Voir aussi, dans le court "Sketch for the Catholic Encyclopedia » : « [...] in 1904, at the Universal Exposition (Louisiane Purchase), St. Louis, Mo., the Grand Prize was awarded to St. Mary's College historical and archaeological exhibit, and 

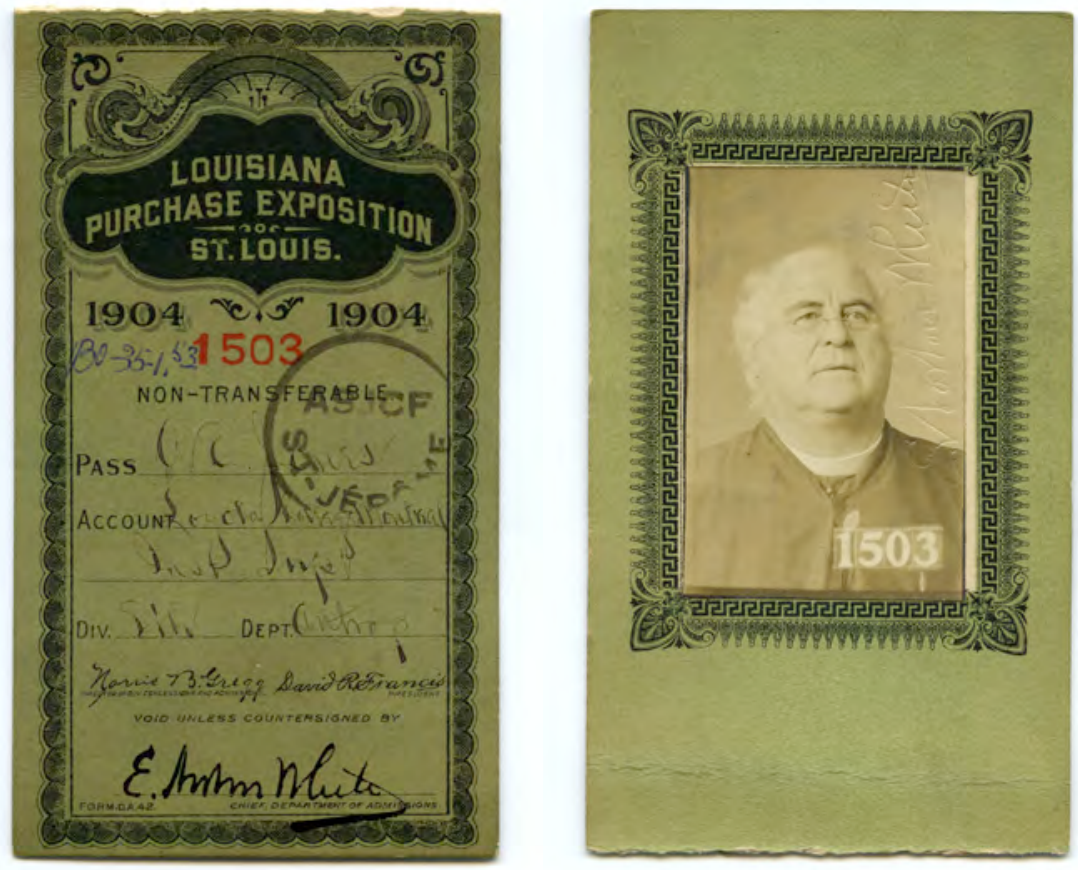

Fig. 16 et 17. Avers et envers du laissez-passer de l'archiviste du Collège SainteMarie, Arthur Edward Jones, s.j., Louisiana Purchase Exposition, 1904 (Exposition universelle de Saint-Louis, Missouri). Archives des jésuites au Canada / The Archive of the Jesuits in Canada, BO-0035.

$\mathrm{Au}$ nombre des cahiers et brochures qui concernent les expositions élaborées par le père Jones à la fin du XIX ${ }^{\mathrm{e}}$ et au début du $\mathrm{XX}^{\mathrm{e}}$ siècle, au moins une importante pièce-repère ou " clé » demeure. Il s'agit d'une copie du catalogue du Special Loan Exhibit de Chicago imprimé en 1904, que l'archiviste annota et augmenta grâce à des feuillets intercalaires en 1914, en plus de lui fournir une couverture, sur laquelle il traça ces mots : 1914. Key to Exhibit Numbers (voir fig. 18, 19 et 20). Les annotations marginales (qui ne semblent pas être toutes de la même main) associaient chacun des documents exhibés à une localisation (l'annotation «Lock. 3 »- pour «Locked » ou « Locker » - laisse penser

Gold Medal to the Archivest, as collaborator, with accompanying diplomas » ( Sketch for the Catholic Encyclopedia », 2. AJC. Fonds Arthur Edward Jones, s.j., BO-0035-1, 30). 
qu'une aire d'exposition ou de rangement spéciale avait été prévue pour les deux livres d'Heures et d'autres documents particulièrement précieux).

Dans la première section de ce catalogue au titre exhaustif ${ }^{82}$, les descriptions des documents rassemblés par le jésuite montréalais se succédaient sous une rubrique qui n'était pas sans rappeler les titres de section de catalogues antérieurs (voir fig. 20) : "Jesuit Historical Collections. Selected from St. Mary's College Archives in Charge of R. F. Arthur E. Jones, S.J., Archivist of St. Mary's College, Montreal, Canada $»^{83}$. De même, les deux livres d'Heures enluminés, datés des XVI ${ }^{e}$ et $\mathrm{XIV}^{\mathrm{e}}$ siècles, figuraient toujours au haut de la liste des documents recensés :

1. 1522 (ante). Illuminated Psalter belonging to the Montholon family.

2. Small illuminated Psalter of the 14th Century ${ }^{84}$.

Bref, si la constance observée dans la présentation des notices favorisa, d'une certaine manière, la mise en exergue des deux manuscrits enluminés, d'un catalogue à l'autre, force est de reconnaître que rien ne perça avec précision sur les voies de transmission qui conduisirent ces livres d'Heures aux Archives du Collège Sainte-Marie. Les Heures de la famille de Montholon se distinguèrent grâce à un patronyme ("Illuminated Psalter belonging to the Montholon family »). Le manuscrit MS- 1 In- $12^{\circ}$ demeura, au contraire, un anonyme petit psautier enluminé ( Small illuminated Psalter»), dont la datation passa erronément du XVI ${ }^{e}$ au XIV siècle.

82. Voir ci-dessous, n. 83.

83. Special Loan Exhibit by the Chicago Historical Society, Dearborn Avenue and Ontario St., During Annual Meeting of the American Historical Association, December 28-30, 1904 : Historical Documents Recently Exhibited in the Louisiana Purchase Exposition [1904], fol. 5r ${ }^{\circ}$ (ou p. 3).

84. Special Loan Exhibit by the Chicago Historical Society, fol. $5 \mathrm{r}^{\circ}$ (ou p. 3). 


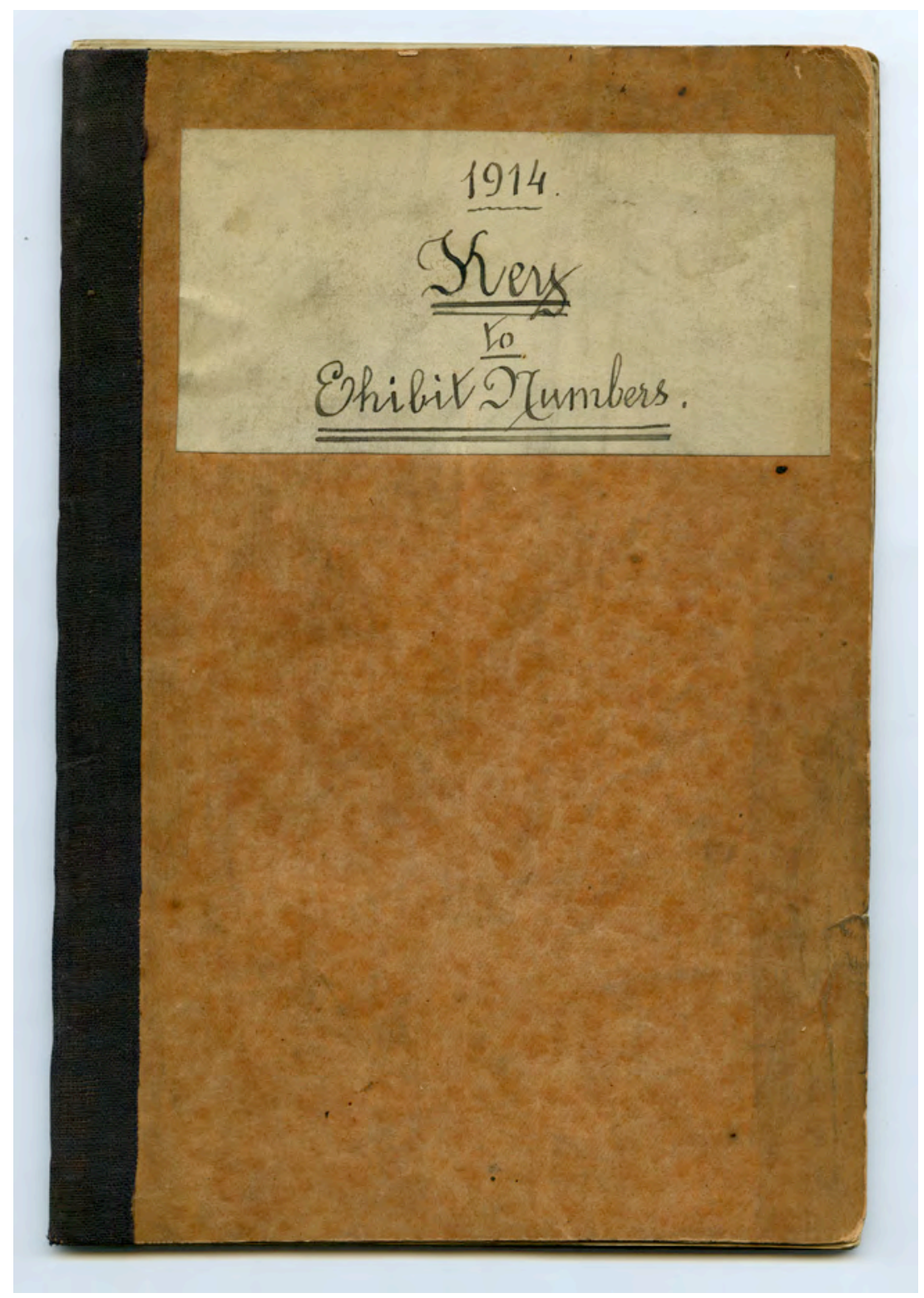

Fig. 18. Couverture du carnet composé par le père Arthur Edward Jones : 1914. Key to E[x]hibit Numbers. Archives des jésuites au Canada / The Archive of the Jesuits in Canada, C-0001, S9, D1. 


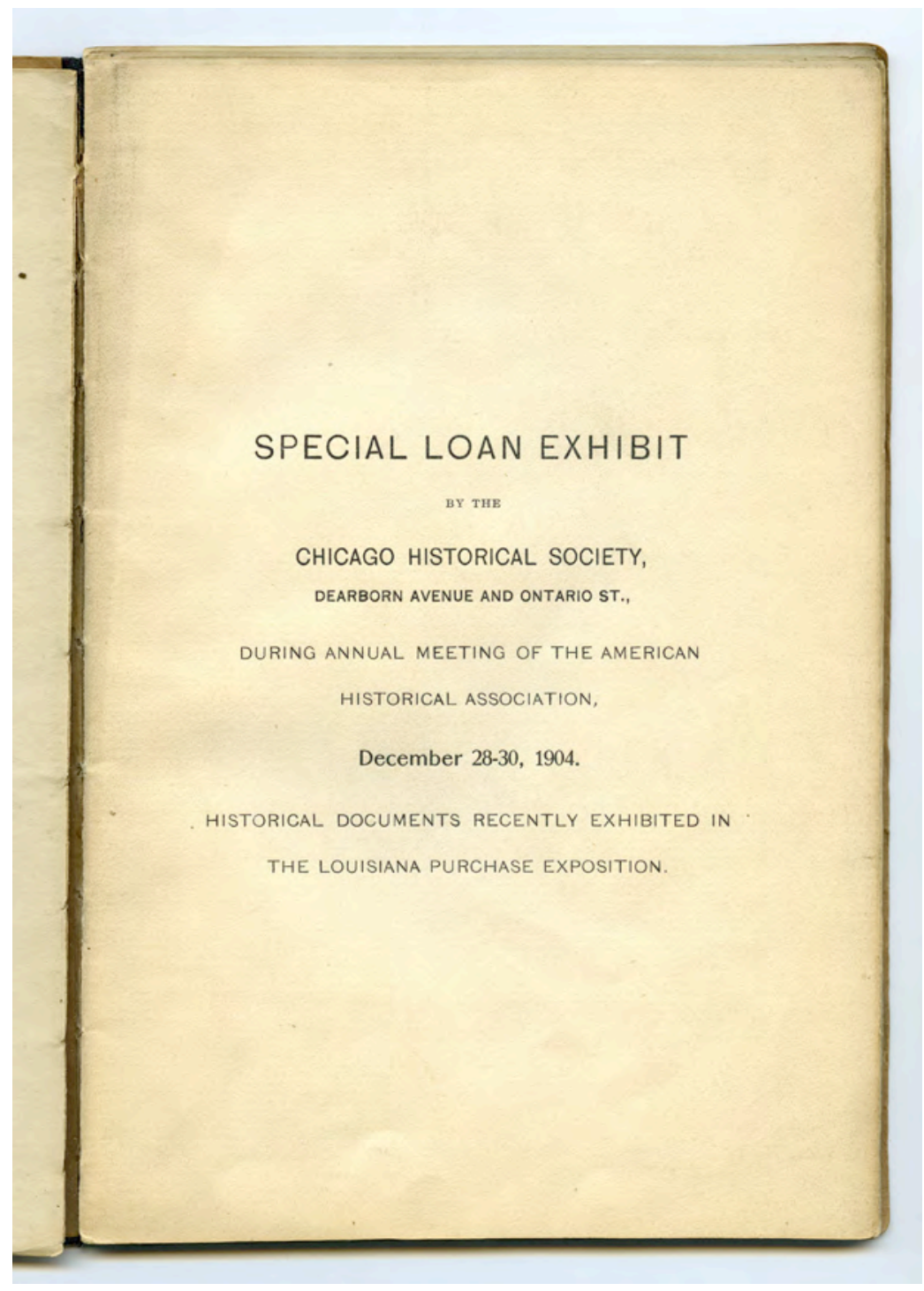

Fig. 19. Special Loan Exhibit by the Chicago Historical Society, Dearborn Avenue and Ontario St., During Annual Meeting of the American Historical Association, December 28-30, 1904 : Historical Documents Recently Exhibited in the Louisiana Purchase Exposition [1904], fol. $3 \mathrm{r}^{\circ}$ (ou p. 1). Archives des jésuites au Canada / The Archive of the Jesuits in Canada, C-0001, S9, D1. 


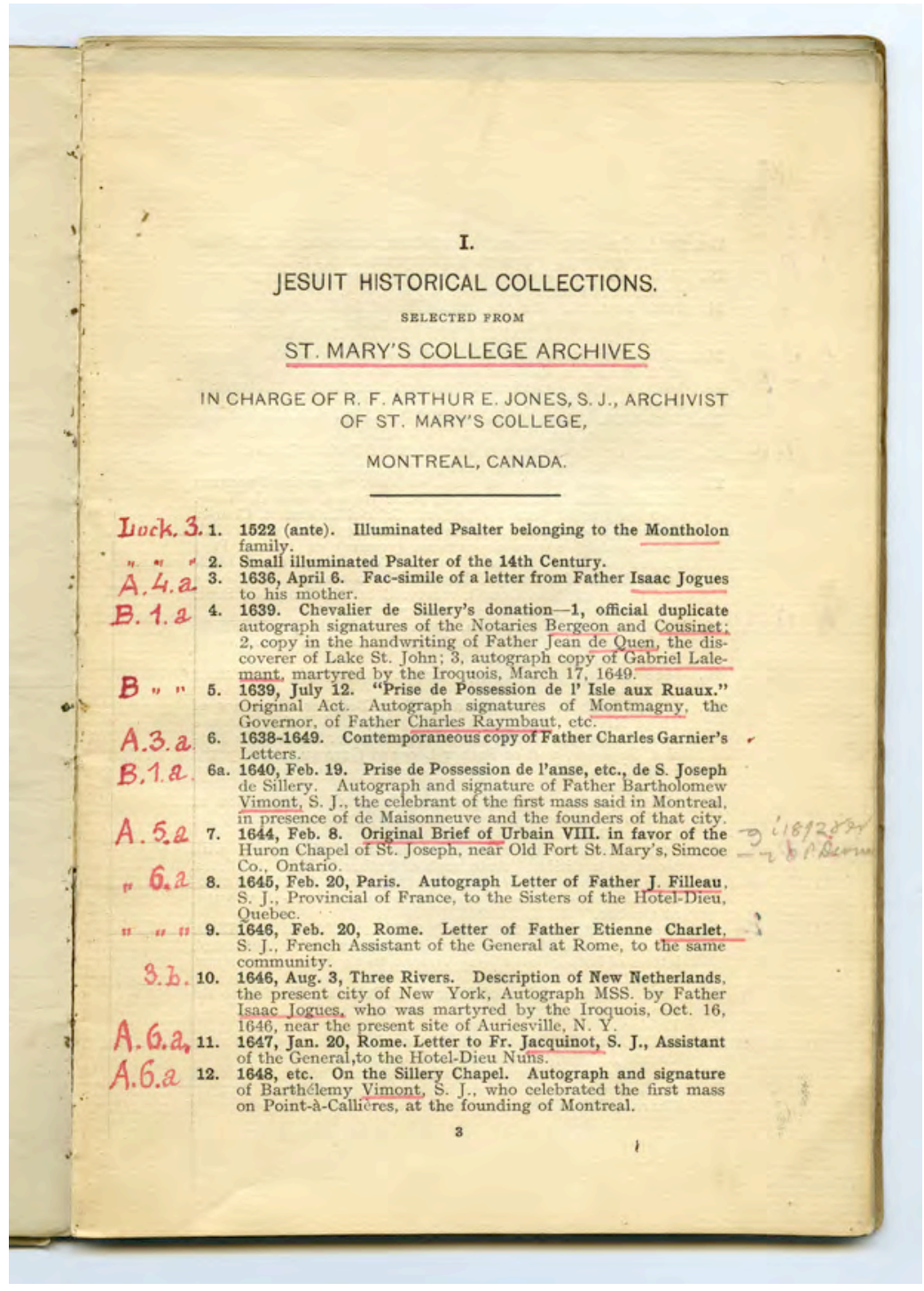

Fig. 20. Special Loan Exhibit by the Chicago Historical Society, Dearborn Avenue and Ontario St., During Annual Meeting of the American Historical Association, December 28-30, 1904 : Historical Documents Recently Exhibited in the Louisiana Purchase Exposition [1904], fol. $5 \mathrm{r}^{\circ}$ (ou p. 3) Archives des jésuites au Canada / The Archive of the Jesuits in Canada, C-0001, S9, D1. 


\section{L'intérêt des bibliophiles pour les Heures enluminées conservées au Collège Sainte-Marie}

Deux articles publiés dans La Presse, le premier, le 7 juin 1938, le second, le 15 octobre 1960, eussent pu offrir quelques connaissances supplémentaires sur les pérégrinations des deux manuscrits. Or, il n'en fut rien, bien que chacun des articles révélât la présence d'un ou deux livres d'Heures enluminés aux Archives du Collège Sainte-Marie. La presse destinée au grand public levait le voile sur ces manuscrits dont les jésuites étaient les gardiens, sans questionner véritablement leur provenance (exception faite d'une allusion à « Jehan Fagot (sic), sieur d'Arbois ", dans l'article publié en 1960), mais en confirmant l'intérêt renouvelé des bibliophiles pour ces précieux artéfacts, grâce au témoignage d'un relieur restaurateur, Philippe Beaudoin, puis à la collaboration d'un historien archiviste, le père Paul Desjardins.

En effet, l'article du 7 juin 1938, intitulé « Vieux manuscrits au collège Sainte-Marie ", rapportait un entretien avec le chef de l'atelier-école de reliure de l'École technique de Montréal, Philippe Beaudoin, qui venait de découvrir plus de quinze parchemins, soit une trentaine de pages de manuscrits, dans la grande bibliothèque privée des pères du Collège Sainte-Marie. Le premier intertitre, "Livres d'Heures », ouvrait une importante parenthèse dans le corps de l'article, puisque les trois paragraphes de cette section (cités ci-dessous) étaient entièrement consacrés aux livres d'Heures conservés par les jésuites. Ainsi, en réponse à la question : «Combien de manuscrits avez-vous découverts récemment ? ", Philippe Beaudoin fit d'abord une mise au point au sujet de la découverte de ces deux livres, avant de souligner leur valeur, le bon état des ors des enluminures, de même que la nécessité urgente de restaurer chacune des reliures :

D’abord, je dois faire remarquer que je n'ai nullement découvert les précieux « livres d'heures » photographiés par un certain journal et dont les lecteurs m'attribuent la découverte. Le R.P.O. (sic) Melançon, qui en a la garde comme archiviste du collège Ste-Marie, en connaissait depuis longtemps toute la valeur et l'intérêt.

Lors de leur examen j'ai pu faire remarquer plusieurs détails quant à la reliure, aux cuirs, aux feuillets de vélin, quant aux ors nombreux et si merveilleusement conservés des enluminures. 
Si l'organisation de la section de reliure me laisse quelques loisirs au cours de l'été, avec la permission des PP. Jésuites, je me ferai un devoir de restaurer la reliure de ces deux livres d'heures dont les couvertures et la couture ne protègent plus suffisamment les feuillets ${ }^{85}$.

Mis au fait de la présence à Montréal d'un riche patrimoine manuscrit, les lecteurs de La Presse ne trouvèrent toutefois dans l'article aucune piste précise quant à l'origine et à la transmission des Heures enluminées, sinon un renvoi allusif au savoir du père Arthur Melançon, qui « en connaissait depuis longtemps toute la valeur et l'intérêt ».

En 1960, le successeur du père Melançon, le jésuite Paul Desjardins, collabora à la diffusion d'une généreuse synthèse sur l'histoire des Archives ${ }^{86}$, dans un article que le journal La Presse publia le 15 octobre, sous le titre « Les trésors historiques du Collège Ste-Marie ${ }^{87}$. Y défilaient les acteurs marquants de cette histoire : le fondateur, Félix Martin, son ami et collaborateur, Jacques Viger, son successeur, Arthur Edward Jones, à propos duquel furent rappelés les honneurs qu'il reçut à la Louisiana Purchase Exposition. Les dons de livres et de manuscrits dont Jacques Viger fut prodigue à l'endroit de la Compagnie de Jésus étaient également salués en ces termes : « En plus d'enrichir la collection du P. Martin de plusieurs volumes, brochures et journaux canadiens, il lui fit don

85. « Vieux manuscrits au collège Sainte-Marie », La Presse (7 juin 1938) : 13 (AJC. Fonds Archives, Collège Sainte-Marie, Q-0001, CACSM 1). Dans le rapport d'expertise préparé par Susanne Marie Holm, responsable de l'atelier de restauration des œuvres sur papier du Centre de conservation du Québec (voir plus haut, n. 3), nous pouvons lire : «Il y a eu une intervention récente pour refaire le dos de chaque œuvre, probablement pendant le $\mathrm{XX}^{\mathrm{e}}$ siècle, si on se fie au caractère de la peau utilisée. Cette restauration n’a pas été camouflée. La couleur des peaux utilisées est différente de la peau originale et les dos de remplacement n’ont pas été décorés du tout, tandis que les couverts médiévaux sont gaufrés. L'intervention est un peu gauche. Les coutures étant un peu trop serrées, les livres ne s'ouvrent pas aussi facilement qu'ils le devraient » (Holm, 1).

86. Le père Paul Desjardins succéda au père Arthur Melançon en 1941 et continua l’ouvre de ses prédécesseurs jusqu’en 1968. "Ce n’est pas tout, écrivait-il dans les Lettres du Bas-Canada, d’avoir en mains un trésor, il faut le mettre en valeur, sous peine dêtre assimilé au dépositaire infidèle » (Desjardins, 36).

87. "Les trésors historiques du Collège Ste-Marie ", La Presse (15 octobre 1960) : 24 (AJC. Fonds Archives, Collège Sainte-Marie, Q-0001, CACSM 1, 3040-5 et Fonds Paul Desjardins, s.j., BO-0085-17, $1)$. 
de certains de ses propres manuscrits ou études...» (« Les trésors historiques du Collège Ste-Marie », 24).

La reproduction d'un feuillet enluminé tiré des Heures de Philippe de Montholon occupait un large espace au bas de l'article, mettant bien en évidence la miniature de l'Adoration des Mages qui accompagne l'heure de Sexte (voir fig. 21, la reproduction du feuillet enluminé original). Pour toute information au sujet des Heures de la famille de Montholon, les lecteurs de La Presse n'eurent cependant accès qu'à cette légende placée sous l'illustration, qui ne manquait néanmoins pas d'attirer leur attention sur la magnificence du document :

OUVRAGE DU XVI ${ }^{e}$ SIĖCLE - Une des pages enluminées d'un livre d'heures (vers 1525) qui a appartenu à Jehan Fagot (sic), sieur d'Arbois et autres lieux. La miniature, admirablement bien conservée, représente l'Adoration des Mages. La lettrine et les arabesques sont rehaussées d'or ; après quatre siècles, les couleurs sont à peine affadies.

(« Les trésors historiques du Collège Ste-Marie », 24)

Rien ne fut dit dans cet article à propos du possesseur Philippe de Montholon ni du plus petit des deux livres d'Heures portant la marque de possession «P Bouthillier» (voir plus haut fig. 1).

\section{Remarques brèves sur la marque de possession « $P$ Bouthillier » et la provenance du manuscrit MS-1 In-12 ${ }^{\circ}$}

Pourtant, malgré ce silence, les rappels fréquents, dans l'article publié en octobre 1960, de la « [g]énérosité de Jacques Viger » («Les trésors historiques du Collège Sainte-Marie ", 24) - qui fut maintes fois soulevée en d'autres lieux - nous incitent à nous demander si ce dernier n'assura pas le passage vers les Archives du livre d'Heures MS-1 In-12 ${ }^{\circ}$, ancienne propriété de "P Bouthillier », vu les rapports étroits qu'il entretint avec le journaliste, interprète, auteur, arpenteur, fonctionnaire et juge de paix Jean-Antoine Bouthillier (1782-1835), fils du marchand et officier de milice montréalais Pierre Bouthillier ${ }^{88}$.

88. Voir Claude Galarneau, «Bouthillier, Jean-Antoine », Dictionnaire biographique du Canada, vol. 6, consulté le 1er juin 2015, http://www.biographi.ca/fr/bio/bouthillier_jean_antoine_6F.html. 


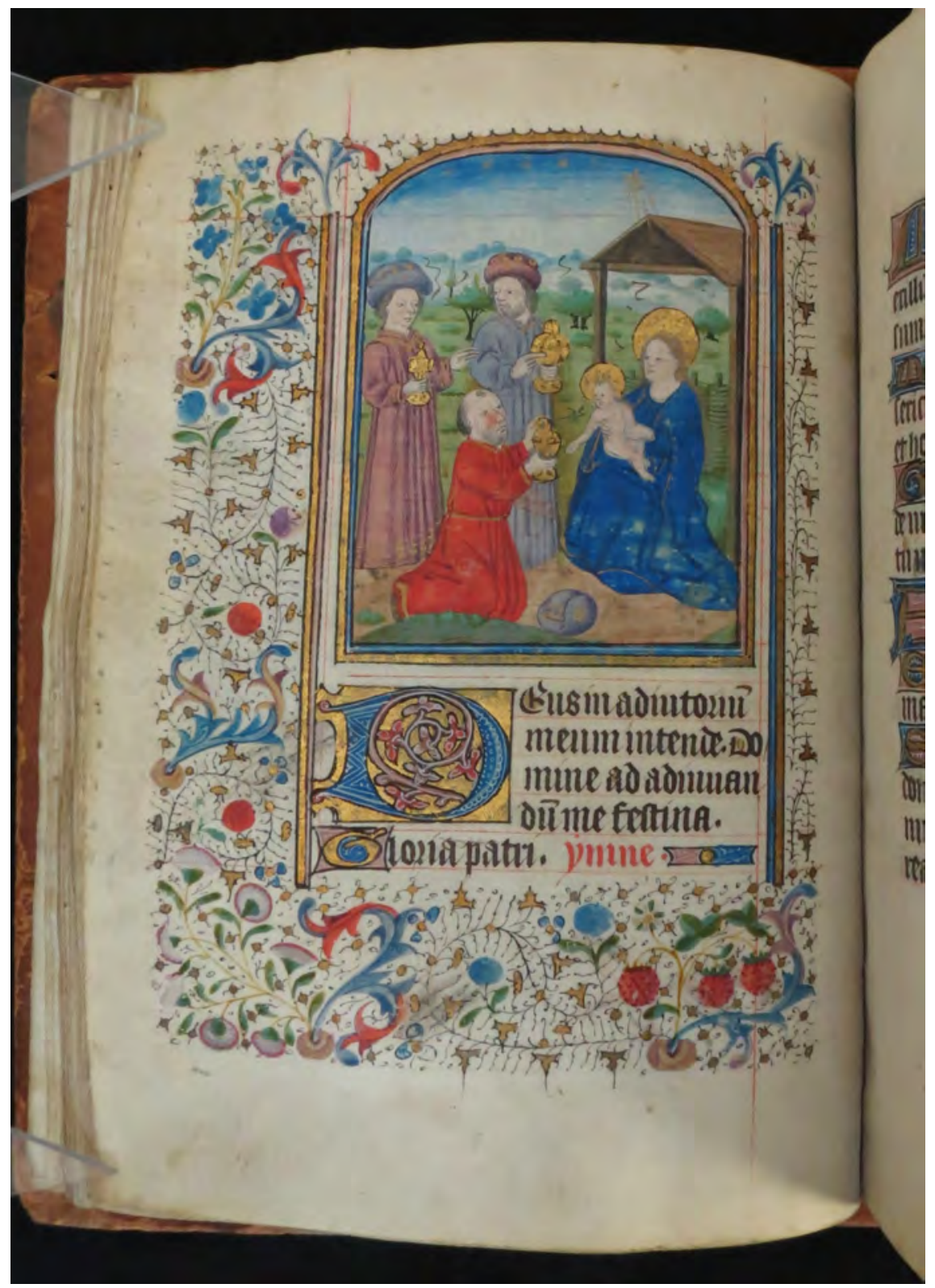

Fig. 21. «Adoration des Mages », manuscrit MS-009-in- $8^{\circ}$. Archives des jésuites au Canada / The Archive of the Jesuits in Canada, 0900-0011.2.1. 
Anciens élèves du Collège Saint-Raphaël dirigé par les sulpiciens, JeanAntoine Bouthillier et Jacques Viger devinrent des collaborateurs au journal Le Canadien au cours de la première décennie du XIX ${ }^{e}$ siècle. Ce journal était consacré principalement à la politique, à la liberté de presse et à la défense des droits des Canadiens français ${ }^{89}$. En novembre 1808, Jacques Viger succéda à la rédaction du journal à Jean-Antoine Bouthillier, qui en avait été lui-même le rédacteur de janvier 1807 à mars 1808. Auteur d'un Traité d'arithmétique pour l'usage des écoles ${ }^{90}$, que l'imprimeur-éditeur, libraire et bibliophile John Neilson ${ }^{91}$ publia en mai 1809 , Jean-Antoine Bouthillier fut le propriétaire d'une bibliothèque évaluée à quelques dizaines d'ouvrages, parmi lesquels se trouvaient des bibles, un Nouveau Testament, l'Imitation de Jésus-Christ, des œuvres de Racine, de Cicéron et d'Horace, des dictionnaires de mathématiques et de traduction, etc. ${ }^{92}$.

Une question nait, spontanément : le manuscrit MS- 1 In- $12^{\circ}$ portant la marque de possession «P Bouthillier » appartint-il au père de Jean-Antoine Bouthillier, Pierre Bouthillier, ou à l'un de leurs ancêtres ? Si tel fut le cas, le fils devint-il, à un moment ou à un autre, le dépositaire de ce livre d'Heures ? Ou ces Heures se retrouvèrent-elles entre les mains de son (ancien) collaborateur, le collectionneur et antiquaire Jacques Viger, qui eût pu agir alors en passeur,

89. Voir Nathalie Hamel, 75 ; Galarneau, « Bouthillier, Jean-Antoine », Dictionnaire biographique du Canada ; Robert, «Viger, Jacques », Dictionnaire biographique du Canada.

90. «Dès les débuts de la Nouvelle-France, les relevés cartographiques exigeaient des connaissances géométriques. Alors que la colonie s’organise et qu'est créé le Collège des Jésuites en 1635, leur enseignement se met en place. C'est à Martin Boutet que revient l'honneur d'être le premier professeur de mathématiques : il enseigne « tout ce qu’il est nécessaire de s'avoir des mathématiques pour ce païs » et instruit « la plupart des capitaines qui conduisent des vaisseaux en ce païs ». Le développement du commerce nécessite la connaissance de la règle de trois, du calcul des proportions et de l'intérêt (simple et composé). Ces méthodes seront présentées pour la première fois par un arpenteur, Jean-Antoine Bouthillier, qui publie en 1809 un Traité d'arithmétique à l'usage des écoles, qui sera réédité au moins jusqu'au milieu du XIX siècle » (Yves Gingras, " 350 ans de mathématiques au Québec », consulté le 13 juin 2015, http://www.cirst.uqam.ca/Portals/0/docs/medias/350_ans_de_mathematique.pdf).

91. John Neilson fut le propriétaire d'une centaine d'exemplaires survivants de la bibliothèque du Collège de Québec fondée par les jésuites en 1632-1635. Ces exemplaires, pour la plupart des XVI ${ }^{e}$ et XVII ${ }^{\mathrm{e}}$ siècles, lui furent remis par le père Jean-Joseph Casot. Ils sont conservés aujourd'hui à la Bibliothèque de la Compagnie de Jésus du Collège Jean-de-Brébeuf, à Montréal. John Neilson posséda aussi quelques exemplaires originaux des Relations des jésuites imprimées par Sébastien Cramoisy (voir Biron, \$25-29). 92. Galarneau, «Bouthillier, Jean-Antoine », Dictionnaire biographique du Canada. 
au bénéfice des jésuites ? Ce ne sont là, une fois de plus, que des conjectures qui méritent, certes, d'être considérées, mais au-delà desquelles il serait bien hasardeux, pour l'instant, de nous prononcer avec certitude.

\section{Les précieux artéfacts d'une histoire collective}

Les Relations et le Journal des jésuites attestèrent la présence de livres d'Heures en Nouvelle-France au XVII ${ }^{e}$ siècle et le fait que de tels livres furent réclamés par les missionnaires auprès de bienfaiteurs européens, au profit, notamment, des malades de l'Hôtel-Dieu de Québec. La présence et la lecture de livres d'Heures, manuscrits ou imprimés, dans la colonie confirmaient que des pratiques de dévotion privées héritées du Moyen Âge et de la Renaissance se perpétuaient et se renouvelaient en Nouvelle-France. Les Heures offertes aux religieux et aux laïcs du Canada par des pourvoyeurs de la mission jésuite furent pour ainsi dire investies d'une seconde vie en Amérique, où elles devinrent les pièces d'une histoire collective, voire, dans certains cas particuliers, les livres-reliques d'une histoire missionnaire.

Les Heures de Philippe de Montholon et le manuscrit MS-1 In- $12^{\circ}$ (ou les Heures Bouthillier) conservés aux Archives des jésuites au Canada figurèrent parmi les manuscrits des premiers missionnaires jésuites en Amérique du Nord dans les catalogues de riches expositions organisées au pays et à l'étranger, en l'occurrence aux États-Unis, au tournant du XXe siècle. Immanquablement, les fonctions de ces Heures du XVe siècle varièrent dans le temps et dans l'espace (depuis Dijon jusqu'à Montréal, en ce qui concerne les Heures de la famille de Montholon). Quand ces deux livres d'Heures furent comptés parmi les manuscrits des missionnaires de la Compagnie de Jésus conservés aux Archives du Collège Sainte-Marie, ils se chargèrent d'une valeur patrimoniale particulière qui allait dorénavant intéresser les historiens, les archivistes et les bibliophiles jésuites et laïcs. Au même titre que tous les artéfacts relatifs à l'histoire de la Compagnie de Jésus au Canada dont la conservation fut assurée, au fil des décennies, par le fondateur, puis par les gardiens successifs des Archives du Collège Sainte-Marie entre 1844 et $1967^{93}$, à savoir les pères Félix Martin, Arthur Edward Jones, Arthur Melançon et Paul Desjardins. 
Le réseau des amitiés et des affinités qui lièrent ces religieux à quelques laïcs érudits (historiens, bibliophiles, collectionneurs, etc.) - ou encore qui lièrent certains de ces laïcs entre eux - constitua, selon toute vraisemblance, l'une des filières par lesquelles circulèrent les livres d'Heures, en particulier le manuscrit MS-1 In- $12^{\circ}$ portant la marque de possession «P Bouthillier». Pour cette raison, il conviendrait, dans le prolongement de la présente enquête, d'explorer les correspondances de Jacques Viger, Jean-Antoine Bouthillier, Georges-Barthélemi Faribault, John Neilson, à supposer que l'un ou l'autre des deux livres d'Heures du XV siècle fût confié aux Archives du Collège SainteMarie par un laïc. De même, il serait pertinent de fouiller des inventaires après décès des membres des familles de Montholon, Fyot de la Marche et Bouthillier pour voir s'ils ne contiendraient pas quelques renseignements sur les routes par lesquelles chacun des deux livres voyagea, avant d'entrer dans les collections montréalaises des pères de la Compagnie de Jésus.

L’année 2017 marque le $375^{\mathrm{e}}$ anniversaire de la fondation de Montréal. L’année prochaine, soit en 2018, le Musée des Beaux-Arts de Montréal accueillera une exposition qui mettra à l'honneur les très rares, soit vingt-six, livres d'Heures (en latin, en français et en flamand) des $\mathrm{XV}^{\mathrm{e}}$ et $\mathrm{XVI}^{\mathrm{e}}$ siècles conservés au Québec. Les Heures de Philippe de Montholon et le manuscrit MS- 1 In- $12^{\circ}$ (ou les Heures Bouthillier) que possèdent les Archives des jésuites au Canada sont donc appelés à renouer avec la gloire que leur assurèrent le $\mathrm{XIX}^{\mathrm{e}}$ siècle finissant et le premier $\mathrm{XX}^{\mathrm{e}}$ siècle, plus précisément avec celle que leur procura l'exposition de 1892, qui commémorait le $250^{\mathrm{e}}$ anniversaire de la fondation de Ville-Marie ${ }^{94}$. À l'instar des catalogues d'autres expositions qui eurent lieu en 1894, 1897, 1899 et 1904, celui de 1892 permettait de constater que, de tous les documents prêtés pour l'occasion par les Archives du Collège Sainte-Marie, les deux livres d'Heures enluminés demeuraient les plus anciens artéfacts d'une histoire collective.

des fonds réunis sous le nom de " Archives de la Compagnie de Jésus au Canada français ». Pour le rappel de leurs transferts, voir n. 4.

94. Voir le catalogue de 1892 mentionné plus haut : A Record of Canadian Historical Portraits and Antiquities Exhibited by the Numismatic and Antiquarian Society of Montreal, 15 $5^{\text {th }}$ September 1892, in Commemoration of the $250^{\text {th }}$ Year of the Foundation of Montreal. 